Approved for public release; distribution is unlimited

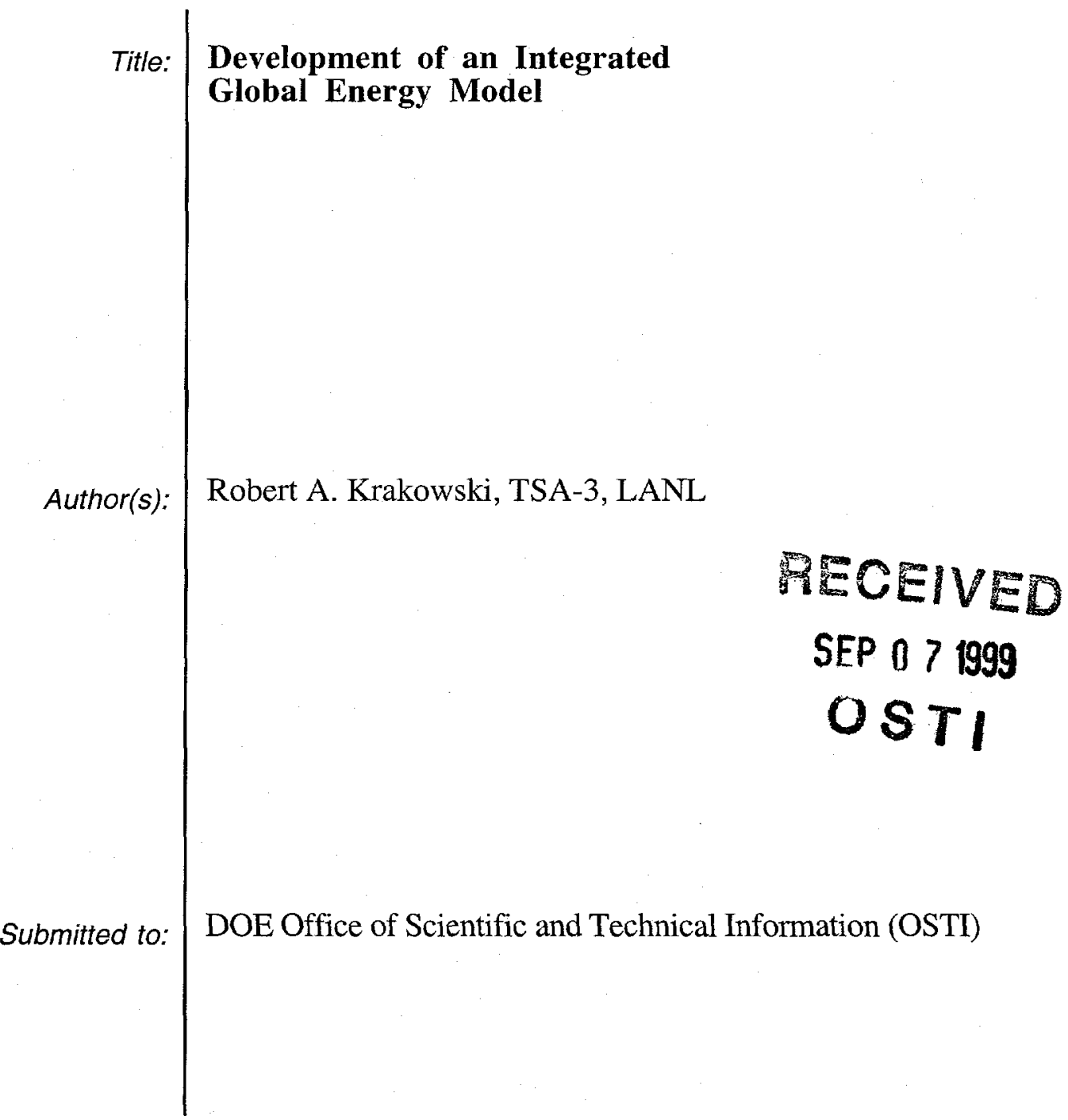

Los Alamos National Laboratory, an affirmative action/equal opportunity employer, is operated by the University of California for the U.S. Department of Energy under contract W-7405-ENG-36. By acceptance of this article, the publisher recognizes that the U.S. Government retains a nonexclusive, royaltyfree license to publish or reproduce the published form of this contribution, or to allow others to do so, for U.S. Government purposes. Los Alamos National Laboratory requests that the publisher identify this article as work performed under the auspices of the U.S. Department of Energy. Los Alamos National Laboratory strongly supports academic freedom and a researcher's right to publish; as an institution, however, the Laboratory does not endorse the viewpoint of a publication or guarantee its technical correctness. 


\section{DISCLAIMER}

This report was prepared as an account of work sponsored by an agency of the United States Government. Neither the United States Government nor any agency thereof, nor any of their employees, make any warranty, express or implied, or assumes any legal liability or responsibility for the accuracy, completeness, or usefulness of any information, apparatus, product, or process disclosed, or represents that its use would not infringe privately owned rights. Reference herein to any specific commercial product, process, or service by trade name, trademark, manufacturer, or otherwise does not necessarily constitute or imply its endorsement, recommendation, or favoring by the United States Government or any agency thereof. The views and opinions of authors expressed herein do not necessarily state or reflect those of the United States Government or any agency thereof. 


\section{DISCLAIMER}

Portions of this document may be illegible in electronic image products. Images are produced from the best available original document. 


\title{
Development of an Integrated Global Energy Model
}

\author{
Robert A. Krakowski* \\ Systems Engineering and Integration Group (TSA-3) \\ Technology and Safety Assessment Division \\ Los Alamos National Laboratory
}

\begin{abstract}
The primary objective of this research was to develop a forefront analysis tool for application to enhance understanding of long-term, global, nuclear-energy and nuclear-material futures. To this end, an existing economics-energyenvironmental $\left(E^{3}\right)$ model was adopted, modified, and elaborated to examine this problem in a multi-regional (13), long-term $(\sim 2100)$ context. The $\mathrm{E}^{3}$ model so developed was applied to create a Los Alamos presence in this $\mathrm{E}^{3}$ area through "niche analyses" that provide input to the formulation of policies dealing with and shaping of nuclear-energy and nuclear-materials futures. Results from analyses using the $\mathrm{E}^{3}$ model have been presented at a variety of national and international conferences and workshops. Through use of the $\mathrm{E}^{3}$ model Los Alamos was afforded the opportunity to participate in a multinational $\mathrm{E}^{3}$ study team that is examining a range of global, long-term nuclear issues under the auspices of the IAEA during the 1998-99 period. Finally, the $\mathrm{E}^{3}$ model developed under this LDRD project is being used as an important component in more recent Nuclear Material Management Systems (NMMS) project.
\end{abstract}

\section{Background and Research Objectives}

The need for a long-term, global energy modeling capability was recognized. As elaborated on in Fig. 1, a significant goal of this project is an improved and quantitative understanding of the connectivities between nuclear weapons (NW), nuclear materials (NM), and nuclear energy (NE). Since the global generation and flow of nuclear material is dominated by nuclear-energy demand, a modeling capability that made the NM-NE connection was essential to understand and maintain perspectives on the overall NW-NM-NE issue.

Consequently, after a survey of existing global energy models, the long-standing and wellproven ERB (Edmonds, Rielly, Barns) $\mathrm{E}^{3}$ (Energy, Economics, Environment) model $^{2}$ was adopted for modification ${ }^{3-5}$ to meet the overall objectives of the project. The modified ERB model elaborated considerably the regional, technology, and economic description of NE, with an emphasis being placed on the nuclear fuel cycle, the temporal and regional flows and inventories ${ }^{3}$, and the assessment of the proliferation potential associated with those NM flows

*Principal Investigator 
and inventories ${ }^{4}$. Since the original impetus for the creating the ERB model was concern over global climate change induced by increased use of fossil fuels ${ }^{2}$, a natural result and capability of the modified ERB model was an ability to compare NM-related risks with those associated with long-term atmospheric accumulations of greenhouse gases ${ }^{6,7}$. The primary objective of the present LDRD project was to: a) to develop a forefront analysis tool for understanding quantitatively the problems of long-term, global, NE and NM futures; b) to create a Los Alamos presence in and contribution to the broader NE/NM community through the use of this integrated $\mathrm{E}^{3}$ model by performing and reporting "niche analyses"; c) to project a Los Alamos expertise in the general area of $\mathrm{E}^{3}$ analyses and assessments through the presentation of technical results at conferences and workshops; and d) to potentially attract out-year funding for the above-described activities while simultaneously advancing modeling capabilities and collaborations.

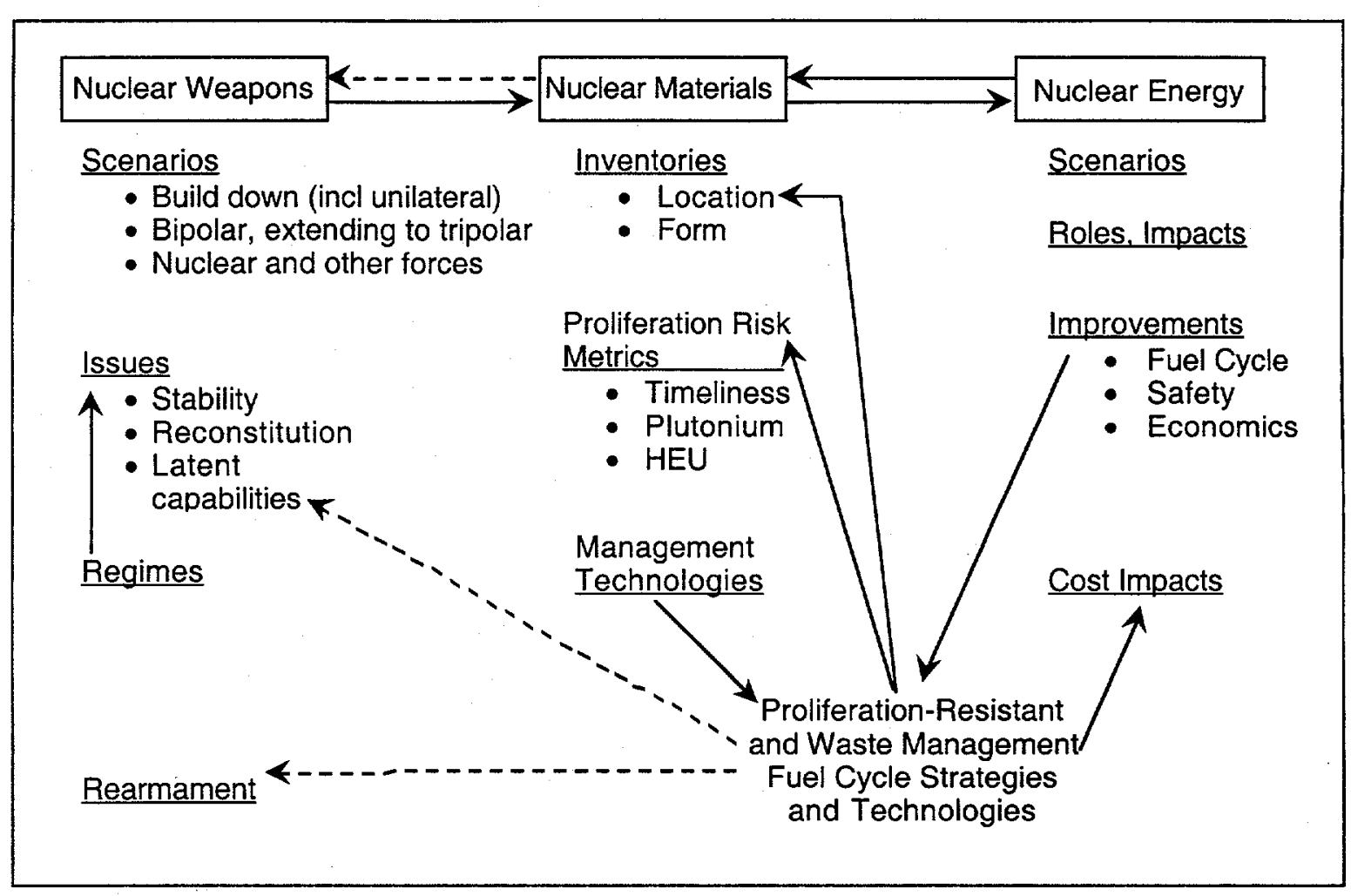

Figure 1. Focus areas that provided the rationale and impetus for the project. 


\section{Importance to LANL Science and Technology Base and National R\&D Needs}

Central to the Laboratory mission is an ability to understand and project the essential elements of and connectivities among the NW-NM-NE focus areas depicted on Fig. 1. Simply understanding the control and disposition of plutonium or enriched uranium released from dismantled NWs is not sufficient in a politically multi-polar world. Growing economic globalization is pushing more for sustainable development under constraints of mitigating global climate change. Key features of such a world, against which NW-NM-NE interactions displayed on Fig. 1 must be weighed, include ${ }^{8}$ :

- enhanced cross-boundary transport of energy technologies and fuels;

- more secure/stable fossil fuel supplies;

- reduced importance of national energy strategies;

- lower/slower long-term economic growth, except in Asia;

- decreasing competitive margins between fossil and fission energy, driven by lower fossilfuel prices, increased efficiencies, reduced-cost clean-coal technologies;

- broader public input to energy policies;

- continued, if not increased, concerns on nuclear safeguards and proliferation in a changing geopolitical and global-economic environment;

- release of large quantities of NM from NW stockpiles;

- higher worldwide NE safety standards extending to a broadening cultural spectrum;

- slowing of short-term and long-term NE deployment, development, and reprocessing;

- intermingling at national levels of energy, environment, and strategic security concerns.

Hence, the development of a long-term vision that adequately charts pathways to goals and endstates, that in turn realize global benefits of nuclear technology while minimizing nuclear dangers, requires a modeling capability that touches on all aspects of "things nuclear" (e.g., NWs, NM, NE, environment, nonproliferation, public acceptance, institutional demands and limitations, etc.). For this reason, the integrated modeling approach depicted heuristically in Fig. 2 and elaborated on a more operational level in Fig. 3 has been initiated and advanced with the resources provided by this LDRD project.

As is shown in Fig. 4, an essential element of the project has been communication through presentations, publications, and more formal collaborations. These are described in the following section, and as is indicated in the publications listed in the subsequent section. 


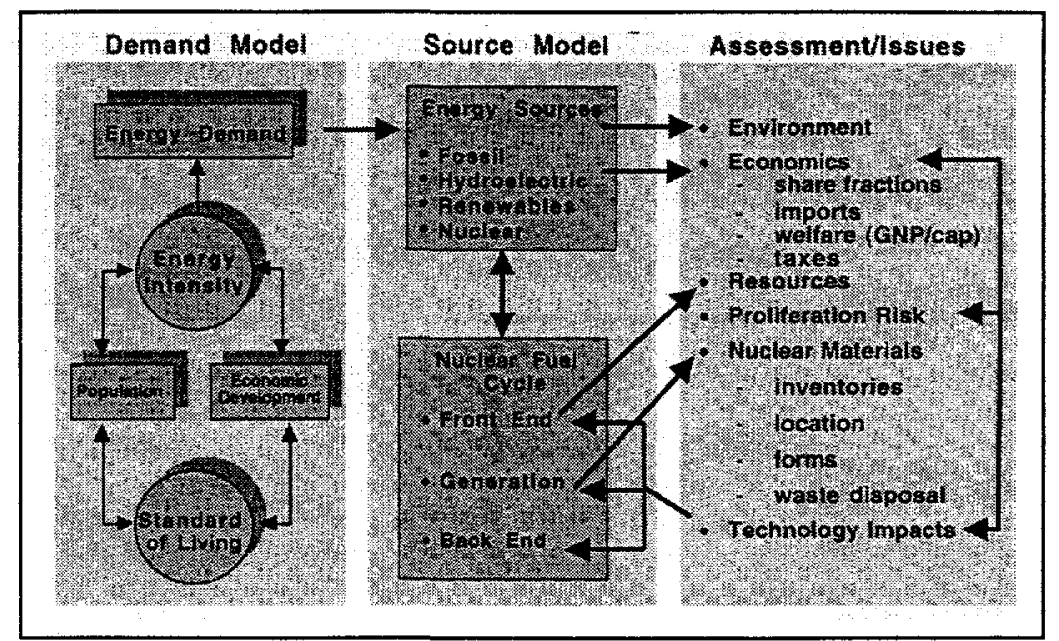

Figure 2. Heuristic depiction of demand-driven modeling approach adopted to access future NE roles, impacts, and issues related to the NW-NM-NE issues and connectivities illustrated on Fig. 1

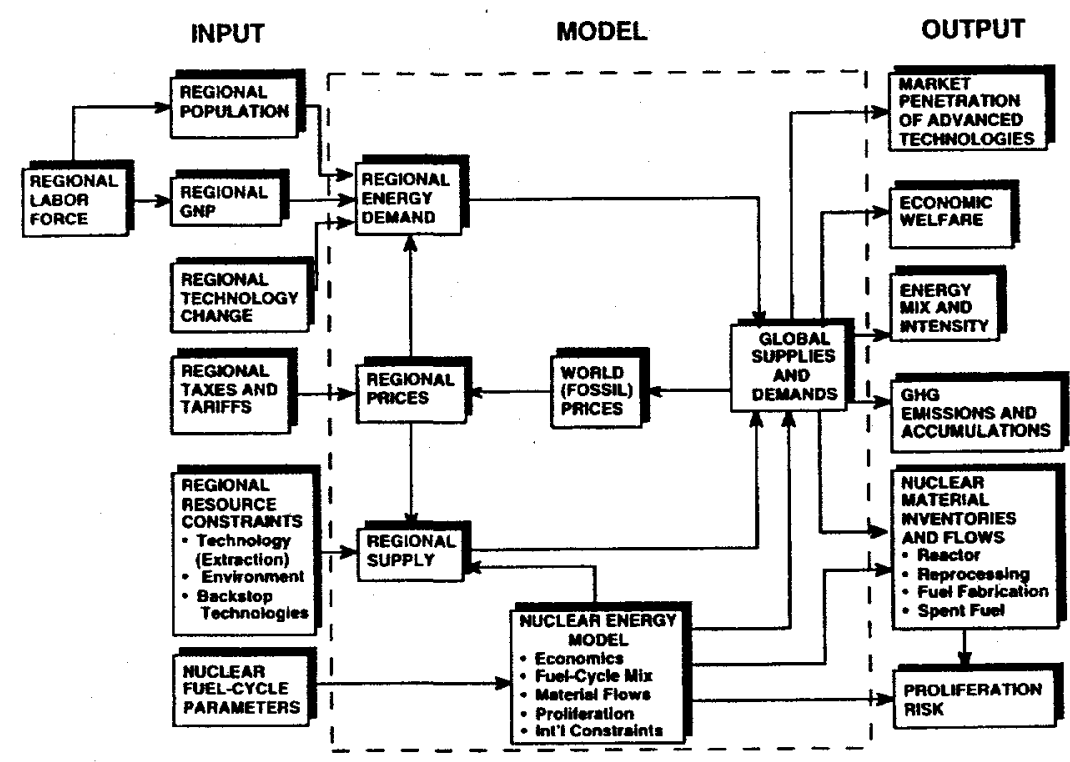

"Edmonds, Reilly, Barns (PNL)

Figure 3. Structural layout of ERB global $\mathrm{E}^{3}$ model ${ }^{2}$; four main components comprise the ERB recursive economic-equilibrium model: energy demand; energy supply; energy balance; and greenhouse gas (GHG) emissions. Relationships between inputs and iterated (to common world fossil-fuel prices) outputs, as well as the addition of a higher-fidelity nuclear-energy model (e.g., resources, costs, nuclearmaterial flows, inventories, and proliferation risk) are also shown. 


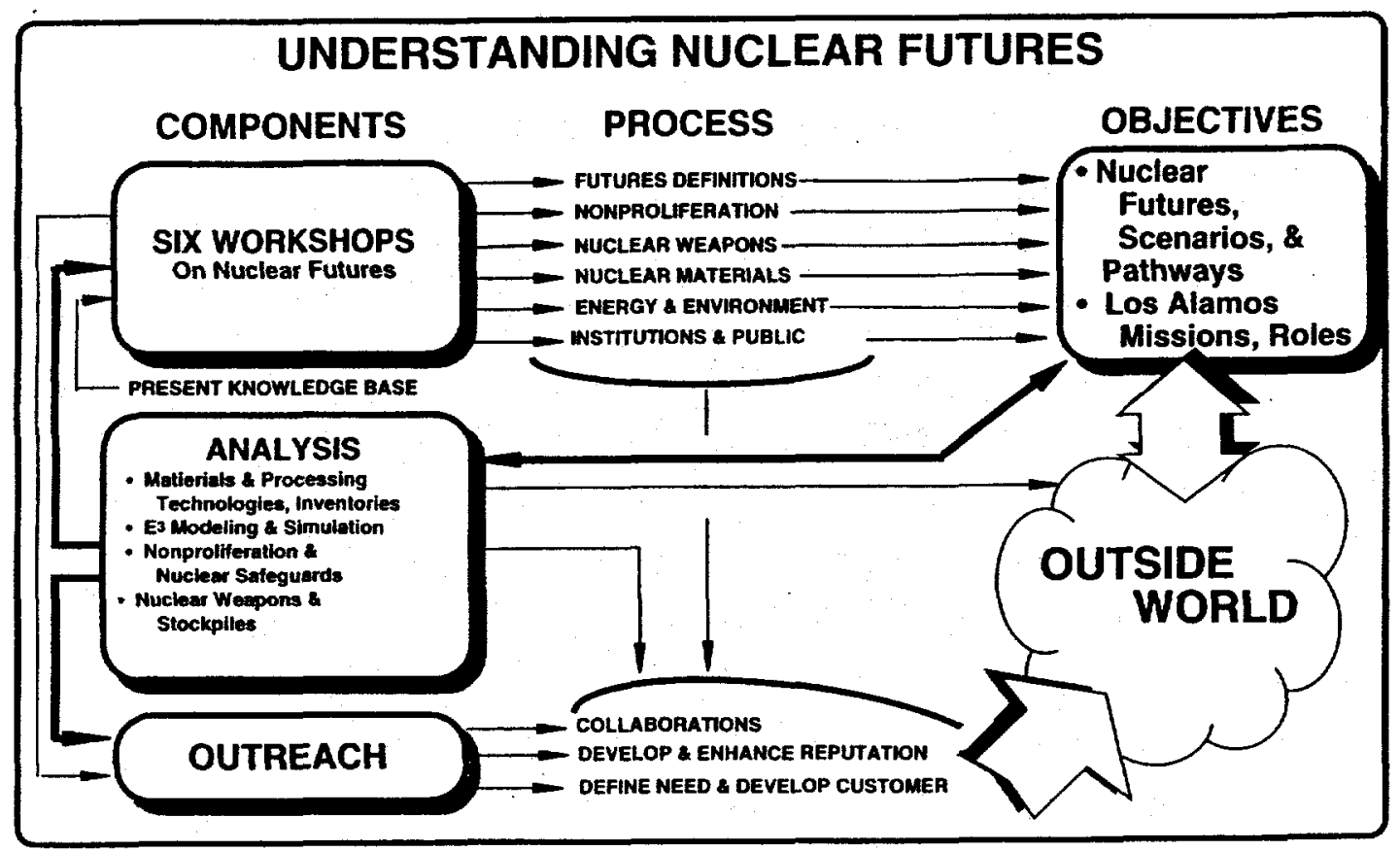

Figure 4. Schematic diagram showing interaction of three primary components: workshops, analysis, and outreach.

In summary, therefore, the following benefits to the Laboratory can and/or have accrued from the development and implementation of the integrated $\mathrm{E}^{3}$ model:

- Provide advanced computational capability for analysis and assessment of important national security topics (energy security, nonproliferation, environmental security);

- Support DOE with advanced modeling/assessment tools in its future mission through mechanisms such as "roadmapping" support (nonproliferation and nuclear energy, responses to global climate change, energy planning/projections, technology/innovation diffusion):

- Foster creativity and stimulate exploration of forefront $S \& T$ (integrated proliferation risk assessments, technology diffusion, population and GDP);

- Serve as a proving ground for new research and support of high-risk, high-value R\&D (integrated proliferation risk assessments, technology diffusion, population and GDP, provide support in a range of programmatic long-range planning activities);

- Provide technical basis for interacting with a wide range of policy/planning/study groups (è.g., DOE, IAEA, NEA/OECD, national/international laboratories/universities/centers, etc.). 


\section{Scientific Approach and Accomplishments}

The guiding philosophy of this research was to adopt/adapt to the greatest extent possible existing, "tried-and-true" modeling tools and approaches, and to apply the resulting model to NW, NM, and NE issues. The partial-economic-equilibrium, multi-regional global ERB (Edmonds, Reilly, Barns) ${ }^{2}$ model was adopted for this purpose and modified as described below. The Integrated Global Energy Model that resulted was then used as an outreach vehicle (Fig. 4) to generate and report results that expressed the long-term implications of a range of NE scenarios in a global, long-term, total-energy context. Details of these studies are reported in the publications listed below.

After describing the modified ERB model, sample results for what was adopted as a Basis Scenario for most of the studies conducted under this project are reported. Finally, the accomplishments associated with the outreach component of this effort are reported in Table I, which gives a listing of key seminars, workshops, conferences, and collaborative efforts that ensued from this project. Finally, interim conclusions and recommendations for future work based on the work given in the Publications section are listed.

\section{Description of Integrated Energy Model}

A qualitative description of the ERB model and modifications made to it are given in this section. A more elaborate description of this recursive, non-optimizing, forced-partialeconomic-equilibrium model of a thirteen-global-region, long-term $(\sim 2100) \mathrm{E}^{3}$ interactions is given in Refs. 2 and 10.

The IEA/ORAU Long-term Global Energy Economics Model ${ }^{2}$, because of its scope, transparency, and generally broad use ${ }^{11-15}$, was adopted as the computational. An operational description of the ERB (Edmonds, Reilly, Barns) model, as it has been modified and applied to the present study, is given in Refs. 10 and 16. The nuclear economics and fuel-cycle model being evaluated "under" the ERB model is also described in Ref. 10, with Ref. 4 describing the recent evolution of the proliferation-risk model. The latter is based primarily on nuclearmaterials flows and inventories within the civilian nuclear fuel cycle, and is synthesized from earlier work reported in Refs. 17-19.

The ERB model is comprised of four main parts: supply, demand, energy balance and GHG emissions (a postprocessor). Supply and demand are determined for six primary energy categories: oil (conventional and non-conventional); gas (conventional and non-conventional); solids (coal and biomass); resource-constrained renewables (hydroelectric and geothermal); nuclear (fission, with fusion being included as a form of solar energy ${ }^{20}$ ); and solar (excluding biomass, includes solar electric, wind, tidal, ocean thermal, fusion, and advance renewable; solar thermal is included under conservation). The energy-balance module assures that supply 
equals demand in each of the thirteen global regions (increased from the nine modeled in the original version ${ }^{2}$ ) depicted in Fig. 5., with primarily electrical energy assumed not to be traded (e.g., assumed to be generated and used within a given global region). Figure 6 illustrates the flows of primary, secondary, and final (energy-services) that occurs in each of the thirteen regions, along with the main drivers of final-energy (FE) demand. While the GHG emissions are computed after global economic equilibrium and energy balance is achieved for each of the nine times that are separated by 15-year time intervals, the nuclear component must be evaluated integrally within the iterative approach to economic and energy equilibrium that forms the heart of the ERB model. Figure 7 gives a simplified layout of the ERB model, with Fig. 3 describing the approach in more elaborate detail under an input-output format and showing in specific detail the $\mathrm{NE}$ additions made to the model.

The demand for energy is determined separately for each of the above-mentioned six primary fuels (Fig. 6) for each of thirteen global regions (Fig. 5) and for each of nine times. As seen from Figs. 3 and 7, five exogenous inputs (including taxes and tariffs) determine the local energy demand. The base GNP (labor-force productivity $\times$ population) is used as an indicator of both (regional) economic activity and as an index of regional income. The base GNP is modified through price elasticities to model energy-economy interactions, with GNP price for energy-rich regions and GNP 1/price for global regions that must import energy.

Improvements in end-use energy efficiency is expressed in the original ERB model as a timedependent index of energy productivity that is independent of energy prices and real income. Through the use of this AEEI-like (Autonomous Energy Efficiency Improvement) factor, scenarios can be examined that span the range from continued improvement to technological stagnation, with these improvements occurring irrespective of world energy prices and real income. The AEEI-like factor used in the ERB model improves the efficiency with which secondary energy is converted to final end-use energy at a rate $\sim 0.5-0.8 \% / \mathrm{yr}$ for most of the results reported herein. World energy prices for all fossil fuels are established through energy balance, with regional (fossil) fuel prices being determined by local taxes, tariff, and transport charges. Interregional trade, however, does not occur for solar, nuclear, or hydroelectric power. 


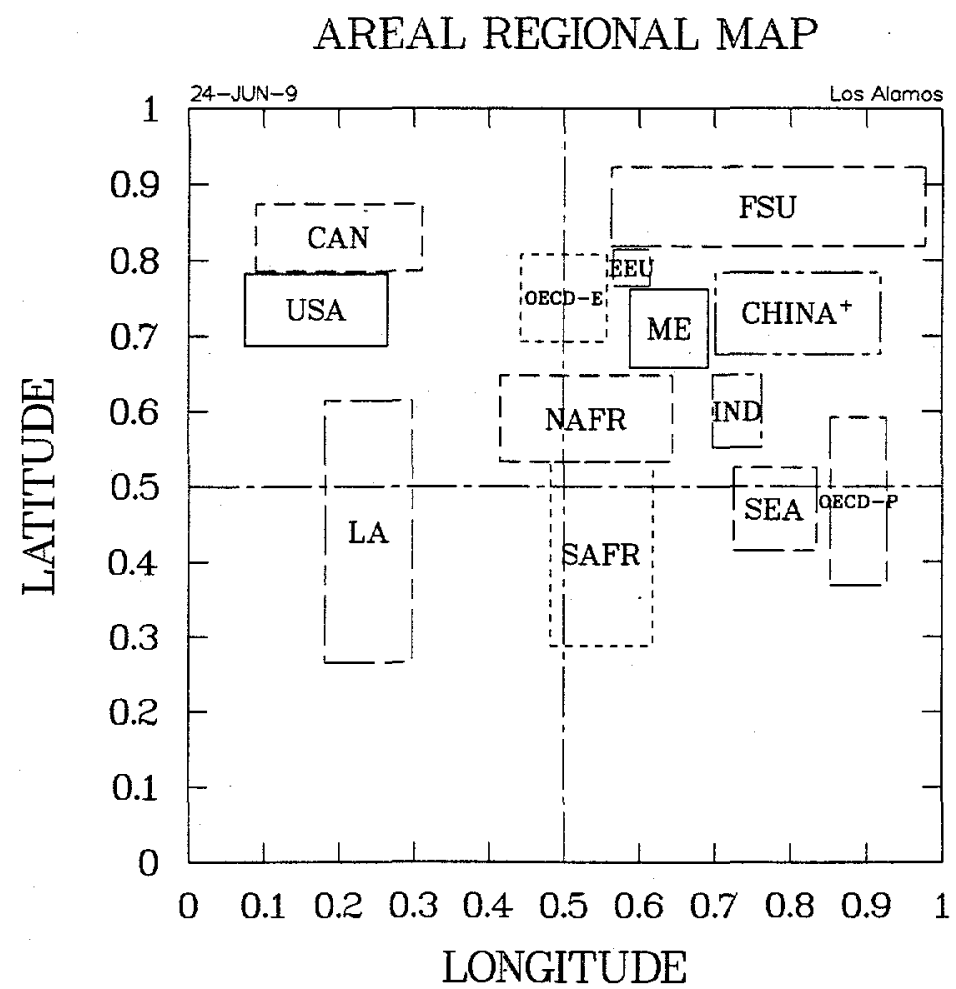

Figure 5. Schematic map of thirteen-region ERB model, with area of each stylized rectangular region reflecting the respective landmasses. The following regional identifiers are used: USA = United States; CAN = Canada; OECD-E = OECD-Europe;

OECD-P = OECD-Pacific; EEU = Eastern Europe; FSU = Former Soviet Union; $\mathrm{CHINA}^{+}=$China plus environs; $\mathrm{ME}=$ Middle East; NAFR $=$ North Africa;

SAFR = Southern Africa; $\mathrm{LA}=$ Latin America; IND = India; and SEA = South and East Asia; Macro-regions are defined as OECD = USA + CAN + OECD-E + OECD-P; REF = EEU + FSU; and DEV = CHINA ${ }^{+}+\mathrm{ME}+\mathrm{IND}+\mathrm{NAFR}+$ SAFR + LA + INS + SEA; also, ROW = DEV - CHINA ${ }^{+}$. 


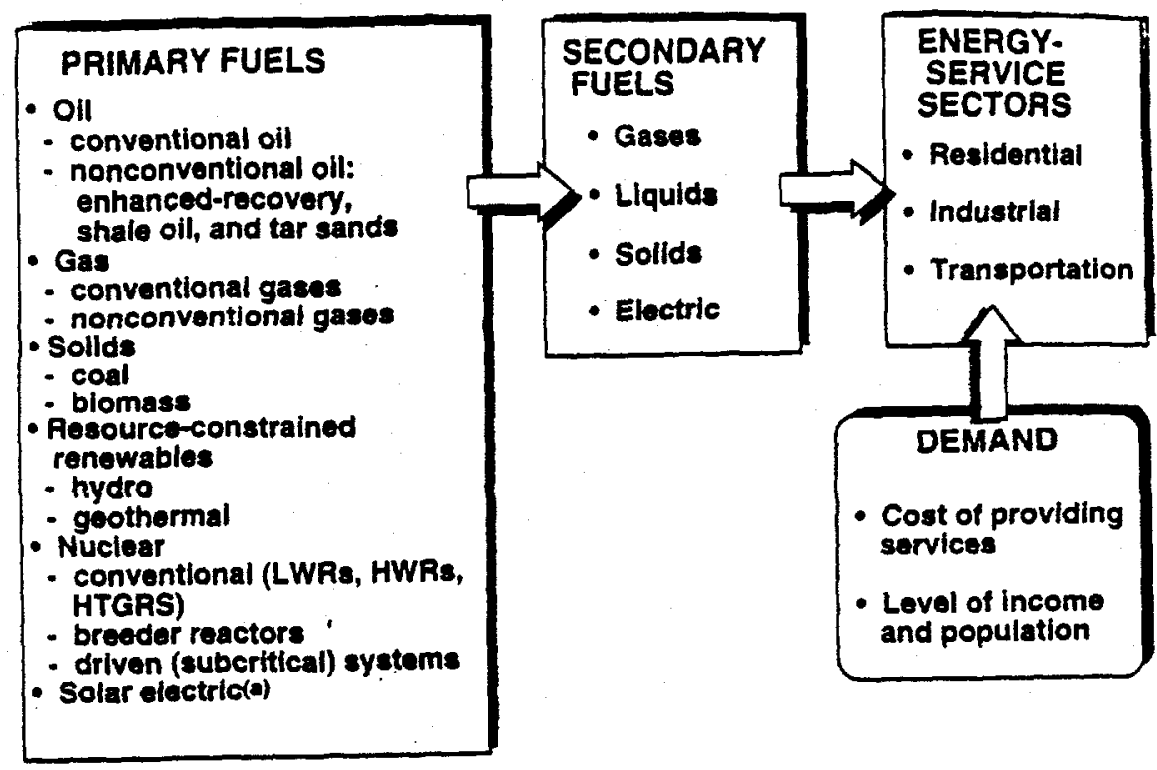

(a) Other (non-electric) solar energy is associated with conservation

Figure 6. Global flow of energy and related services.

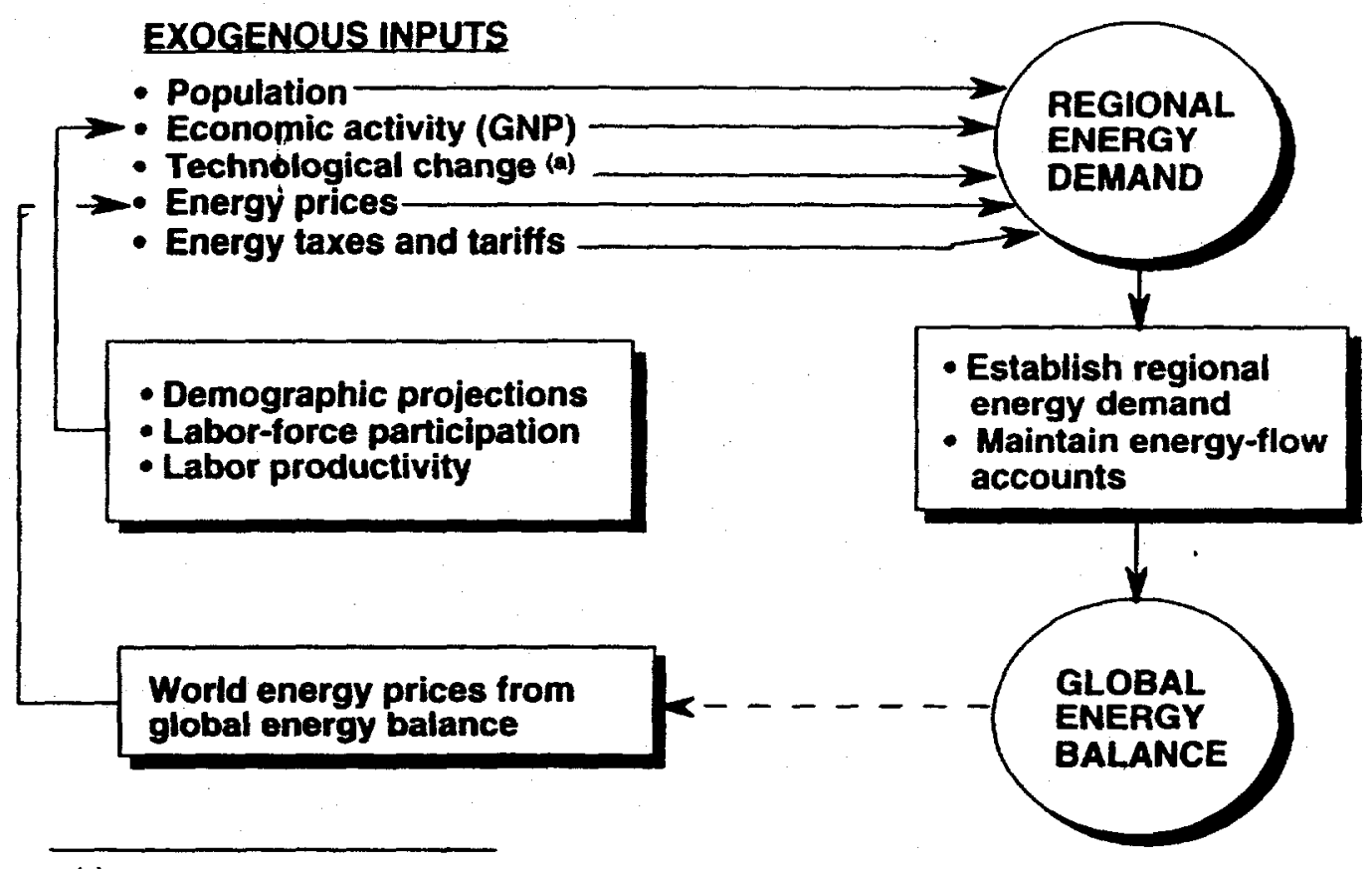

(a) nomprice-driven improvement in energy production

Figure 7. General layout of ERB global $E^{3}$ modeling approach ${ }^{2}$, showing five exogenous inputs for each of thirteen regions (Fig. 5). 
The demand for energy services (e.g., residential/commercial, industrial, and transportation) for each of thirteen global regions is determined by: a) the cost of providing these services; $b$ ) the level of income ( GNP); and c) the regional population. Energy services are energized by an array of four secondary fuels (Fig. 6, i.e., liquids, gases, solids, and electricity). The mix of these secondary fuels used to provide a given energy service is determined by a cost-based market-share algorith $\mathrm{m}^{2}$, as is the demand for fuels used to produce electricity and the share of oil and gas transformed from coal and biomass. The four secondary energy sources are generated from the six primary fuels, with nuclear, hydroelectric, and solar providing only electrical secondary energy; non-electric solar is treated as a conservation technology to reduce the demand for the three-marketed fuels (e.g., oil, gas, and solids). The tracking of primary $\rightarrow$ secondary $\rightarrow$ energy services conversion is analytically modeled using Leontief-type formulation ${ }^{21}$. The second important function of the energy demand module is to maintain a set of energy flow accounts.

As is elaborated in Ref. 16, the nuclear module added to ERB replaces the Leontief input-output coefficients for nuclear, which in the original ERB model ${ }^{2}$ was based only on a scaled cost of uranium extraction (treated in ERB in this regard like a fossil fuel), with one based on capital, operating and maintenance (O\&M), fuel-cycle and decontamination and decommissioning (D\&D) costs. These costs are then fed back to the ERB energy demand module to determine the respective market-share fraction for $\mathrm{NE}$ as a function of time and region. The NE model that is evaluated "under" the ERB model is based largely on an LWR/LMR reactor mix, where the degree of plutonium recycle as mixed uranium-plutonium oxides (MOX) in the LWR is exogenously varied as a function of time and region. Similarly, the LMR breeding ratio, BR, is exogenously varied. The LWR/LMR mix is determined from a cost (COE-minimizing) algorithm that is evaluated for each time and region separately from the price-based market-clearing algorithms that are used in ERB to determine the primary-energy mix; only a single, optimized NE energy price is given to the latter algorithm, with the LWR/LMR mix being determined largely by uranium resource consumption (cost) and the relative fuel-cycle (FC) and capital costs of the LWR (for a given level of MOX recycle) and the LMR (for a given specific inventory and breeding ratio). Additionally, the economic impacts of including actinide-burning, power-generating Fast Spectrum Burners (FSBs, such as non-breeding LMRs or Accelerator-Driven Systems, ADS, can be accessed with the NE model presently evaluated "under" the ERB model.

The energy supply module estimates the supplies for all regions and fossil fuels on the basis of the (iterating) world prices, the cumulative usage, and the cost of recovery (including environmental costs) at a given resource grade. Additionally, region-dependent total extraction costs are decreased in time (for a given grade of resource) to reflect advances in mining 
technologies. Energy supplies are desegregated into two categories: a) renewable (hydroelectric, solar photovoltiac, biomass, and nuclear fission breeder); and b) non-renewable (conventional and unconventional oil, natural gas, coal, and non-breeding nuclear fission). The used of a graded resource base (for fossil and nuclear energies) allows the importance of the fuel resource base to be tested. Fuels like oil shale (and possibly fusion) are considered "backstop" technologies, in that they present a small resource at a low cost, but can transform into a large resource at high costs. A given resource is active and able to contribute to the demand only if the primary-energy price delivered to the energy supply module exceeds the production cost, and if the resource has not been exhausted. Reference 10 summarizes the resource assumptions embodied in ERB, except the uranium resource database has been replace by that reported in Ref. 22 . While the majority of results reported here are base on the resource-versus-grade(cost) assumptions originally developed for the ERB model $^{2}$, the impacts of a more recent (and optimistic) fossil-energy resource database ${ }^{23}$ was examined. $^{26}$

Energy balance across regions is established by a set of rules ${ }^{2}$ for choosing the respect prices that are needed for supply to equal demand in each energy-service group for each fuel. The specific test of convergence requires that the difference in regional sums of demand and supply for each of the three fossil primary fuels (oil, gas, and solids) be less than a specified value.

The ERB model originally tracked only $\mathrm{CO}_{2}$ emission, with $\mathrm{CH}_{4}$ and $\mathrm{N}_{2} \mathrm{O}$ being added later. Appropriate carbon-emission coefficients (GtonneC/EJ) are applied at points in the energy flow where carbon is released to the atmosphere; carbon flows where oxidation does not occur must also be taken into account. Unlike the nuclear model, evaluation of GHG emissions are made after the main computational sequence is completed and economic equilibrium is achieved at each of nine times. To the original ERB model has been added an integral response function ${ }^{24}$ that has been fitted to the results from an ocean/atmosphere circulation model $^{25}$ in order to relate $\mathrm{GHG}$ emissions to atmospheric accumulations and the mean global surface temperature rise that results. These atmospheric $\mathrm{CO}_{2}$-accumulation and average temperature-rise parameters represent interim metrics that remain to be extended to measure quantitative impacts, such as changes in GNP.

The nuclear model developed and implemented for operation "under" the ERB global $\mathrm{E}^{3}$ model performs primarily three functions: a) determines a "top-level" cost estimate in terms of a cost of electricity that is reformed into the Leontief coefficients used to determine costs and market shares, as described above; b) tracks the flow of key elements throughout the nuclear fuel cycle [e.g., natural uranium (NU), low-enriched uranium (LEU), plutonium (PU), and spent fuel (SF)] for use in subsequent waste and proliferation-risk assessments; and c) performs a multi-attribute utility analysis (MAUA) of proliferation risk from the civilian fuel 
cycle. The costing and material-stream flows are described in Ref. 10, whereas the details of the MAUA-based proliferation-risk assessment are elaborated in Ref. 4. Figure 8 schematically illustrates the overall fuel-cycle (FC) components, in addition to depicting the plutonium flows and accumulations for the LWR fuel cycle (both once-through and with plutonium recycle) primarily considered in these studies. Summaries of each of these components of the nuclear model are given in Refs. 10 and 16.

Before costs, material flows/inventories, or proliferation risks can be estimated, characteristics of the fuel cycle must be specified. The nuclear model reported in Ref. 10 is based only on the U/Pu cycle, as utilized in each global region at each time interval by an economically determined ratio of LWR and LMR systems. The LWR in a given global region operates along an exogenously determined MOX recycle trajectory that exponentially transcends from an initial MOX core fraction, $\mathrm{f}_{\text {MOX }}^{\circ}$, to a final MOX core fraction, $\mathrm{f}_{\mathrm{MOX}}^{\mathrm{f}}$, with a time constant $\tau_{\text {MOX }}$. The LMR system, if economics and technology diffusion time constraints allow, is introduced with a pre-assigned breeding ratio, BR. Efforts to manage plutonium inventories through regional and temporal control of $\mathrm{f}_{\mathrm{MOX}}$ and $\mathrm{BR}$ parameters to date have not been extensive. Generally, plutonium is assumed to flow freely between global regions, where deficits is some regions are assume to be corrected by flows from regions with excess plutonium, as long as the global plutonium remains positive. Detailed plutonium balance and control remains for future work and a more detailed nuclear and costing models. Specifically, inter-regional NM flow constraints, breeding ratios driven by inventory and NM need requirements, and/or cost- and/or sanction-based selections of MOX recycle fraction area important areas of future work. 


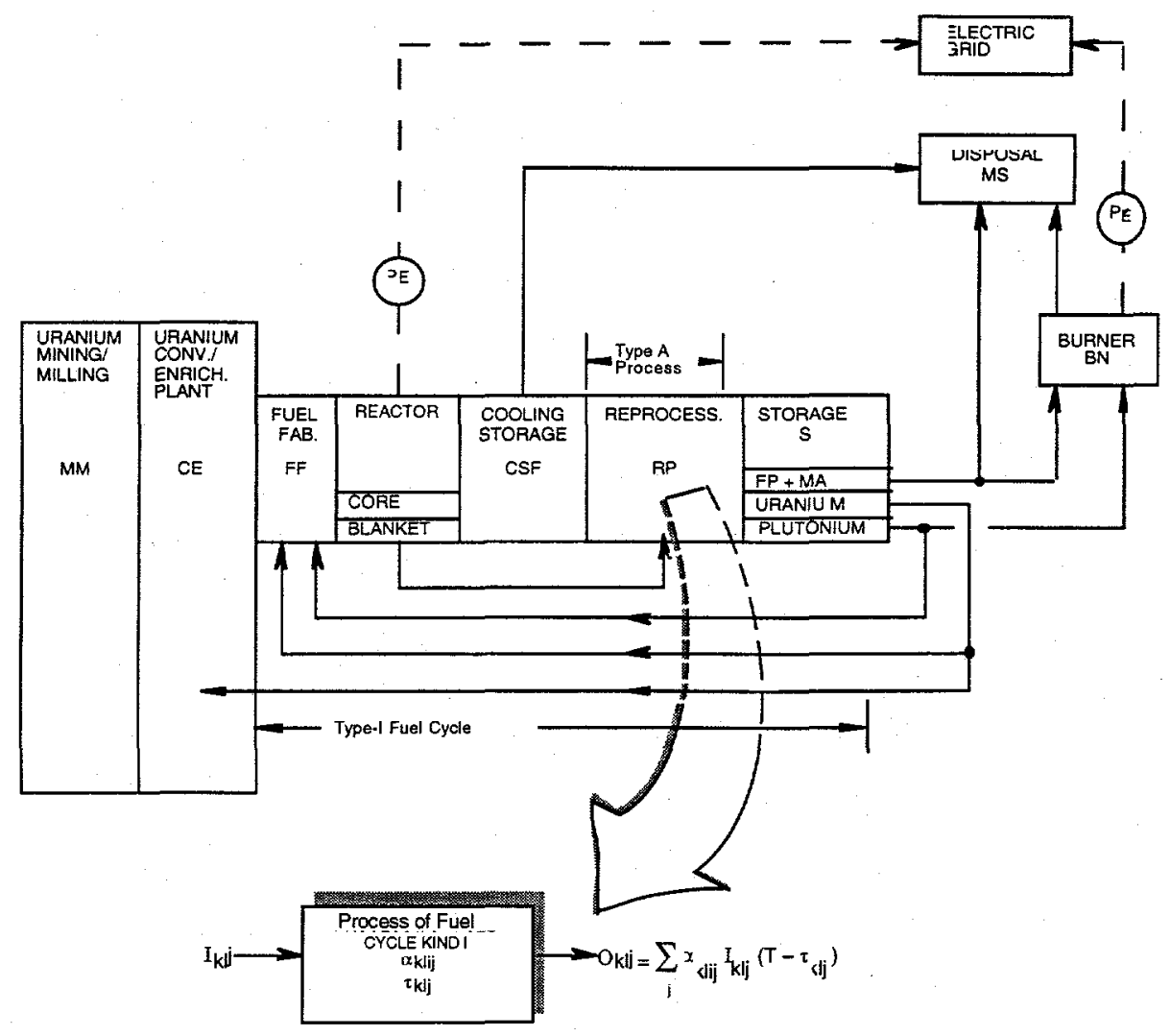

Figure $8 \mathrm{~A}$. Schematic diagram showing relationships of key components modeled in the nuclear fuel cycle.

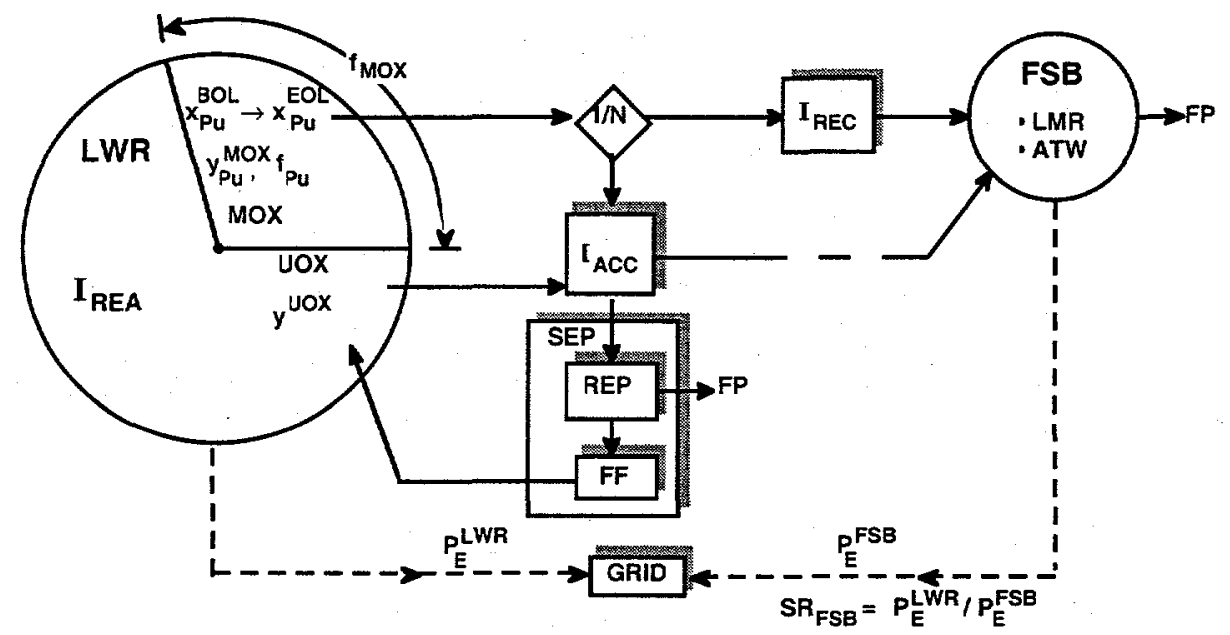

Figure 8B. Schematic diagram of nuclear materials model used in ERB; nuclear materials (plutonium) flows between reactor (REA), spent fuel (ACC $=$ LWR-recyclable and REC = LWR non-recyclable plutonium), reprocessing (REP), and fuel fabrication (FF), will all separated plutonium identified as SEP = REP + FF; possible integration with a Fast-Spectrum (plutonium) Burner (FSB $=$ LMR or ATW) is indicated. 


\section{Sample Results from Integrated Global Energy Model}

Most of the studies using the ERB Integrated Global Energy Model used a "businessas-usual" (BAU) Basis Scenario as a reference or "point-of-departure" case. This Basis Scenario is described here to give a flavor of the kinds of results generated from this LDRD project. The most recent summary of Los Alamos contributions to the IAEA E ${ }^{3}$ Study $^{26}$ gives a comprehensive picture of how these scenario-based studies are used to provide policy guidance. The Ref.-26 study focussed on a BAU and an Ecologically Driven (ED) scenario, both of which considered a standard-growth or Basic Option (BO) and a phase-out (PO) case for NE; the Basis Scenario reported below corresponds to the BAU/BO case.

The World demand for the six classes of primary energy [PE, e.g., oil, gas, solids, nuclear, solar (PV), and hydroelectric] are show for the BAU/BO Basis Scenario as a function of time on Fig. 9. Figure 10A collects the time dependencies of key global parameters for this case, with Fig. 10B giving PE, GNP, and primary-energy intensity, EI = PE/GNP, growth rates. The time evolution of regionally aggregated values of primary-energy intensity and percapita primary-energy demand are shown on Fig. 11, with Fig. 12 giving cross correlations among EI, per-capita GNP, and per-capita primary-energy demand for both aggregated regions and for the thirteen ERB regions (Fig. 5). While each region included on Fig. 12. shows a considerable variation, a composite dependence indicated per-capita GNP increasing at least linearly with per-capita primary-energy demand, with a composite-average elasticity of 1.2-1.3.

Three key metrics are generated by the ERB model for use in assessing the impacts of the four cost-driven NE scenarios: GNP, GHG emission, and nuclear material (plutonium) accumulations, $\mathrm{M}_{\mathrm{Pu}}^{\mathrm{i}}$, of form i ( $\mathrm{i}=\mathrm{REA}, \mathrm{ACC}, \mathrm{REC}, \mathrm{SEP}$ ). Derived parameters, such as per-capita GDP, primary-energy intensity, atmospheric $\mathrm{CO}_{2}$ accumulations and related implications for surface temperature rise or proliferation risk, follow from these primary metrics. Additionally, shifts in the magnitude and mix of primary-energy demand resulting from these cost-driven NE scenarios provide added information for use in impact assessments. Most of these primary or secondary metrics, however, do not yet provide a means for a common-basis comparison and/or tradeoff, and the development of such a common basis remains both a limitation of the present work and an important area of future work (e.g., common-basis comparison of risks associated with decreased productivity, global warming, and nuclear proliferation). 


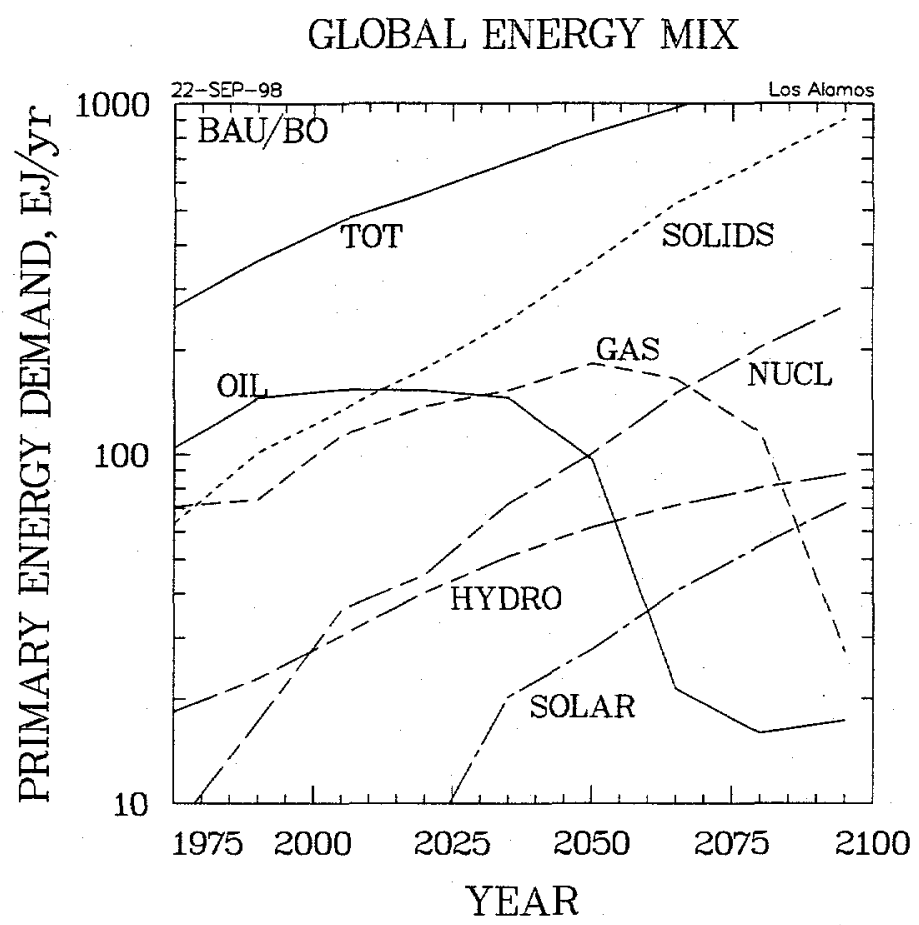

Figure 9A. Time evolution of the six primary energies (Fig. 6) for the BAU/BO Basis Scenario, showing each separately.

CUMULATIVE GLOBAL ENERGY MIX

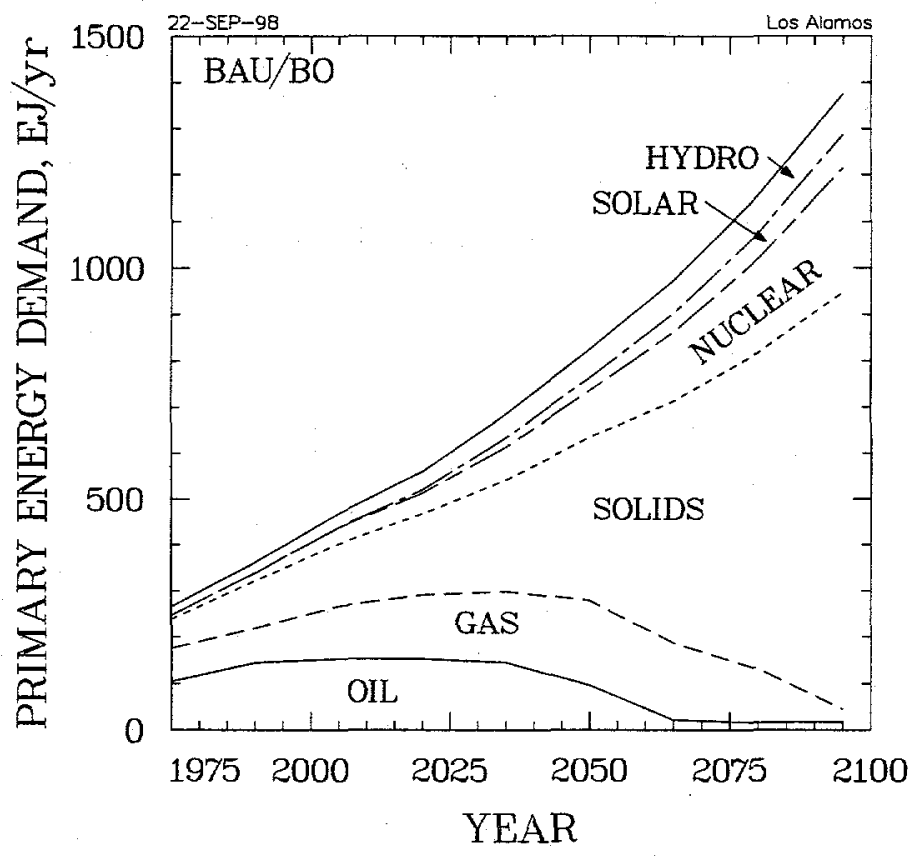

Figure 9B. Time evolution of the six primary energies (Fig. 6) for the BAU/BO Basis Scenario, showing each cumulatively. 


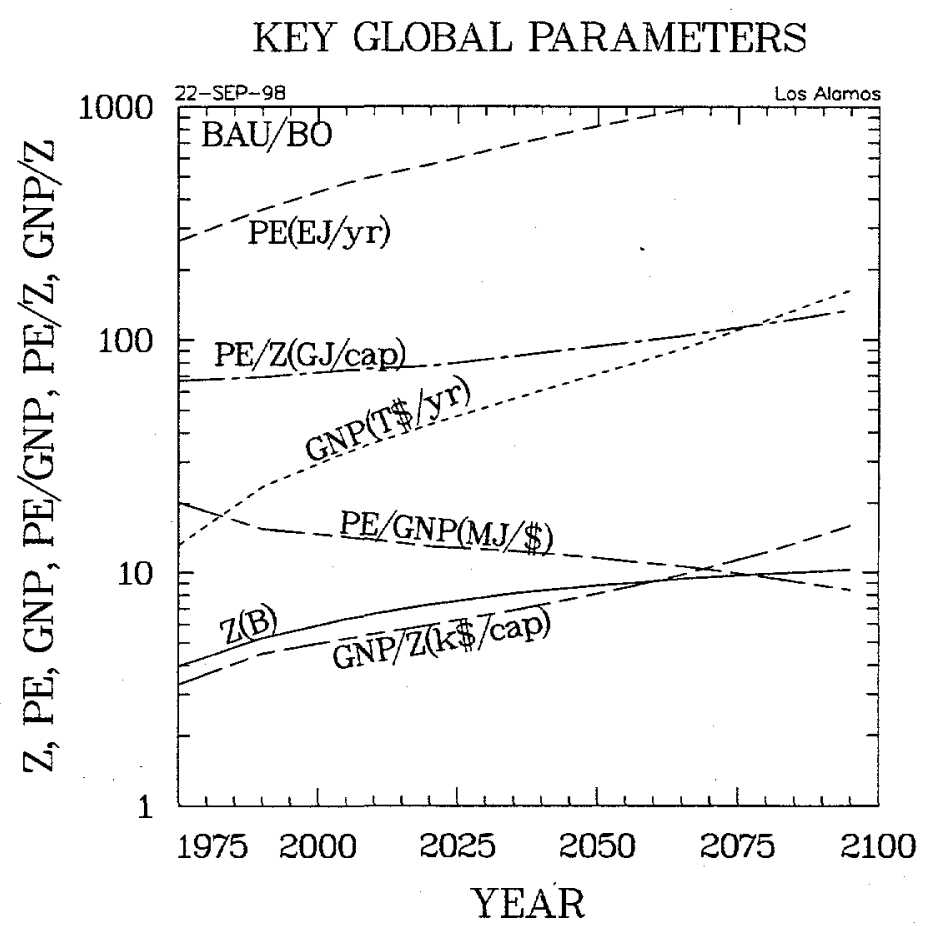

Figure 10A. Time evolution of a summary of key global parameters for the BAU/BO Basis Scenario: population (Z), primary-energy demand (PE), GNP, primary-energy intensity (PE/GNP), per-capita primary-energy demand (PE/Z), and per-capita GNP (GNP/Z).

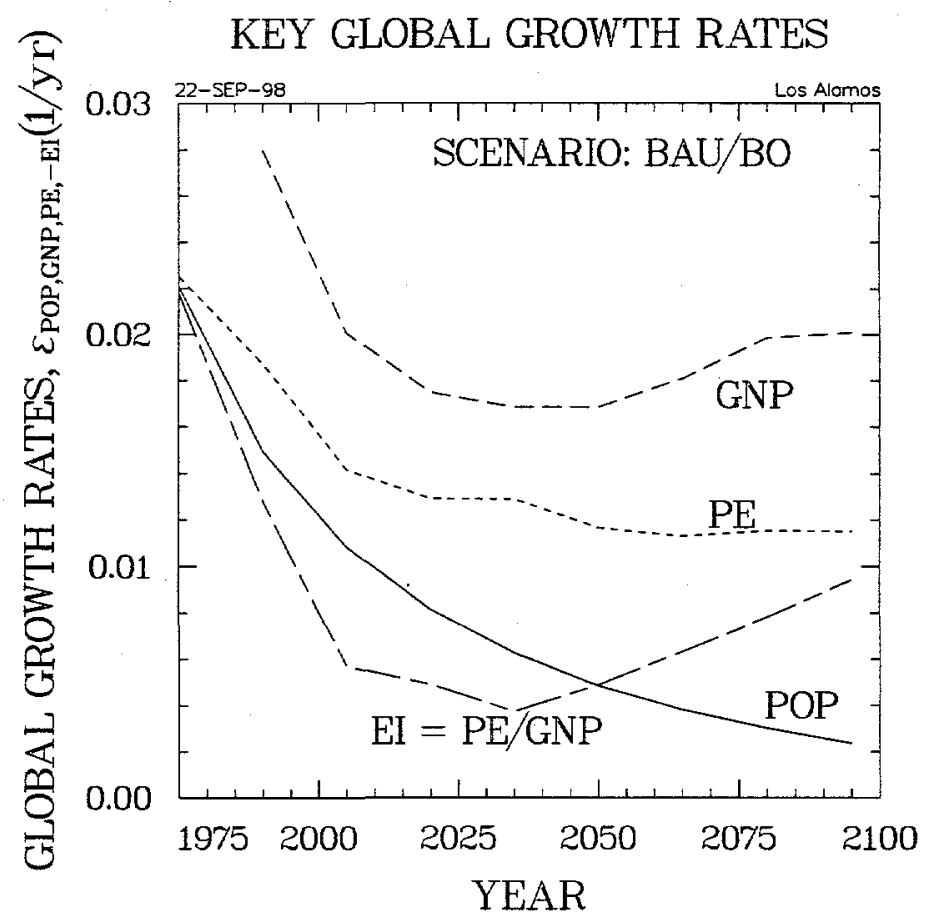

Figure 10B. Growth rates for key global parameters depicted on Fig. 11A. 


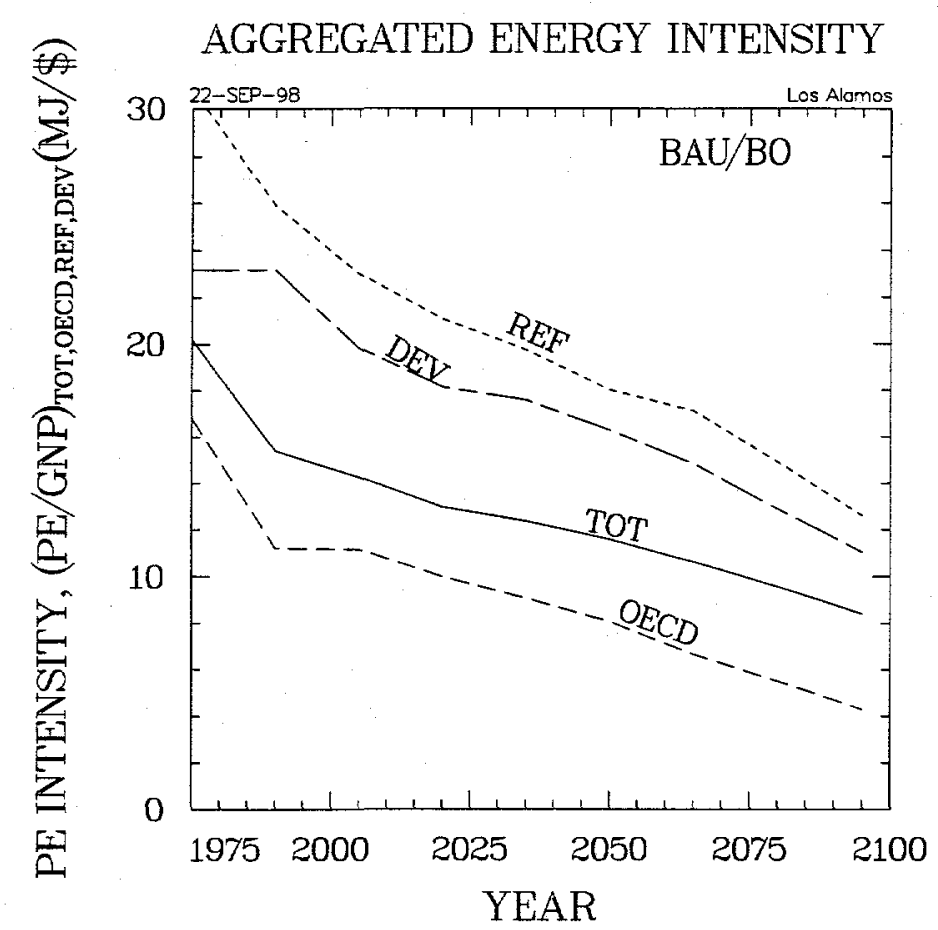

Figure 11A. Evolution of primary-energy intensity for the BAU/BO Basis Scenario, showing total world (TOT), OECD, Reforming Economies (REF = FSU + EEU), and Developing (DEV) countries.

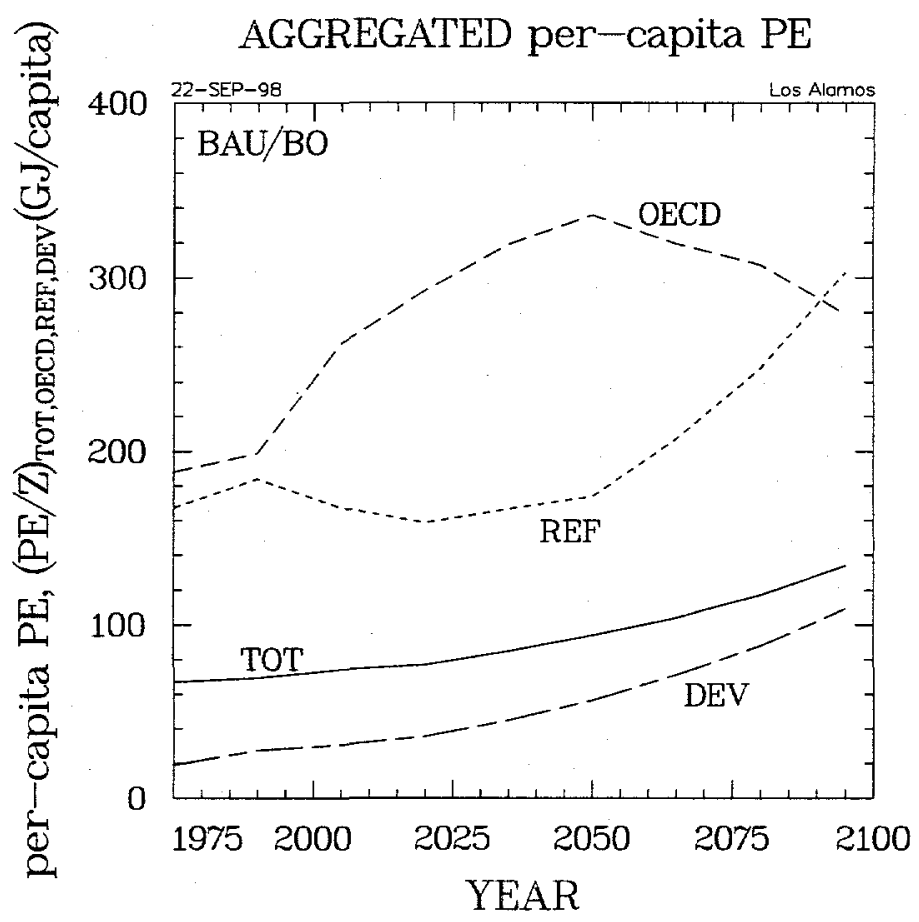

Figure 11B. Evolution of per-capita primary energy demand for the BAU/BO Basis Scenario, showing total world (TOT), OECD, Reforming Economies (REF = FSU + EEU), and Developing (DEV) countries. 
AGGREGATED PE/GNP vs GNP/CAP

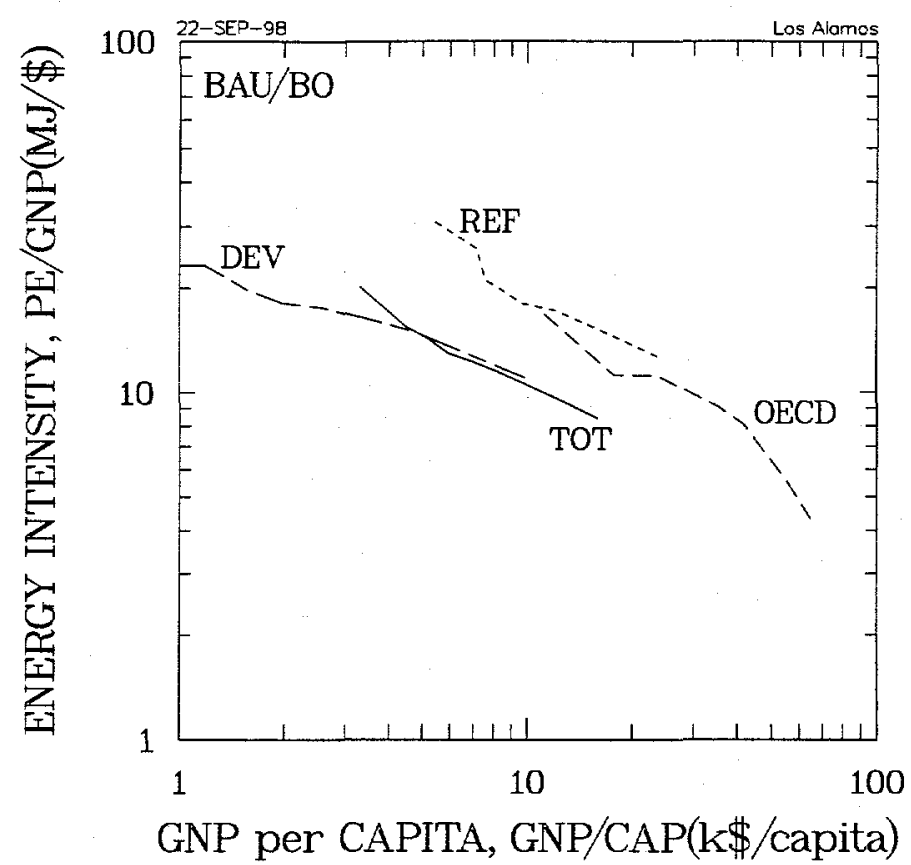

Figure 12A. Correlation of primary-energy intensity with per-capita GNP for the BAU/BO Basis Scenario, showing total world (TOT), OECD, Reforming Economies $(\mathrm{REF}=\mathrm{FSU}+\mathrm{EEU})$, and Developing $(\mathrm{DEV})$ countries .

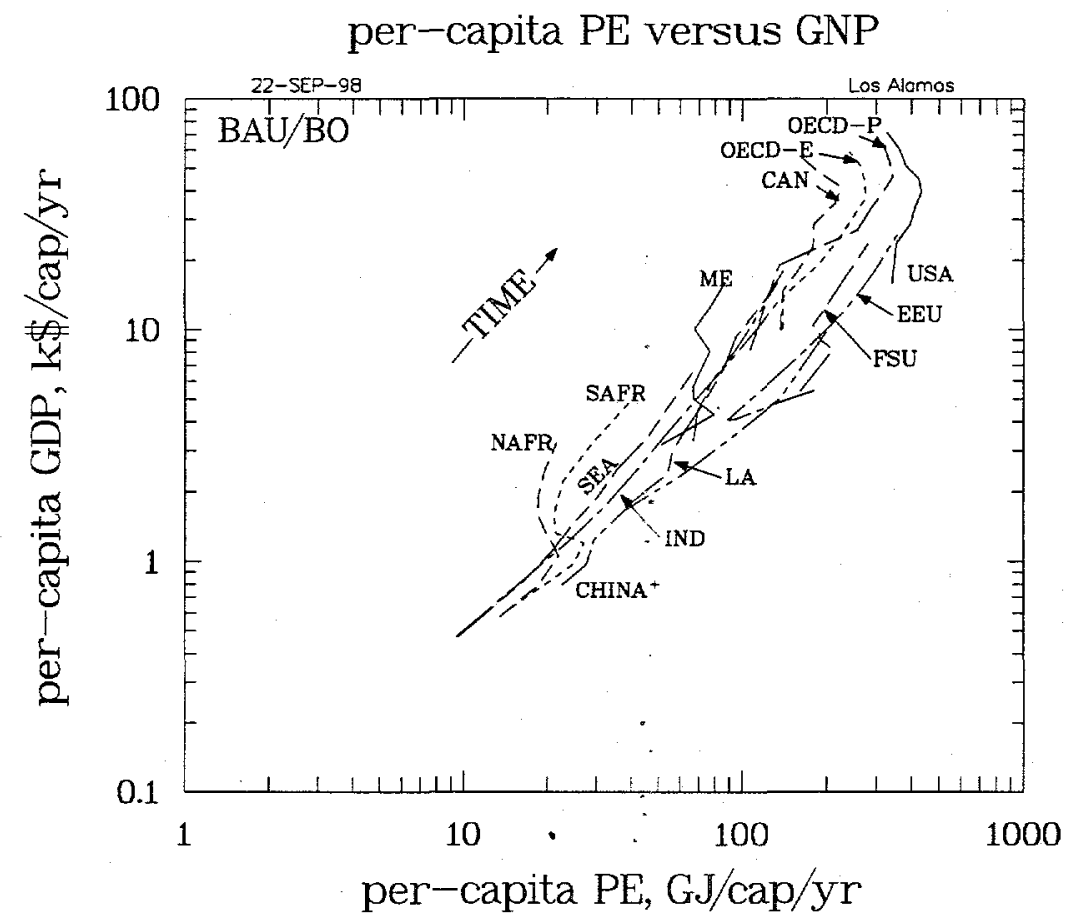

Figure 12B. Correlation of per-capita GNP with per-capita primary-energy demand for the BAU/BO Basis Scenario for all thirteen ERB regions depicted on Fig. 5. 


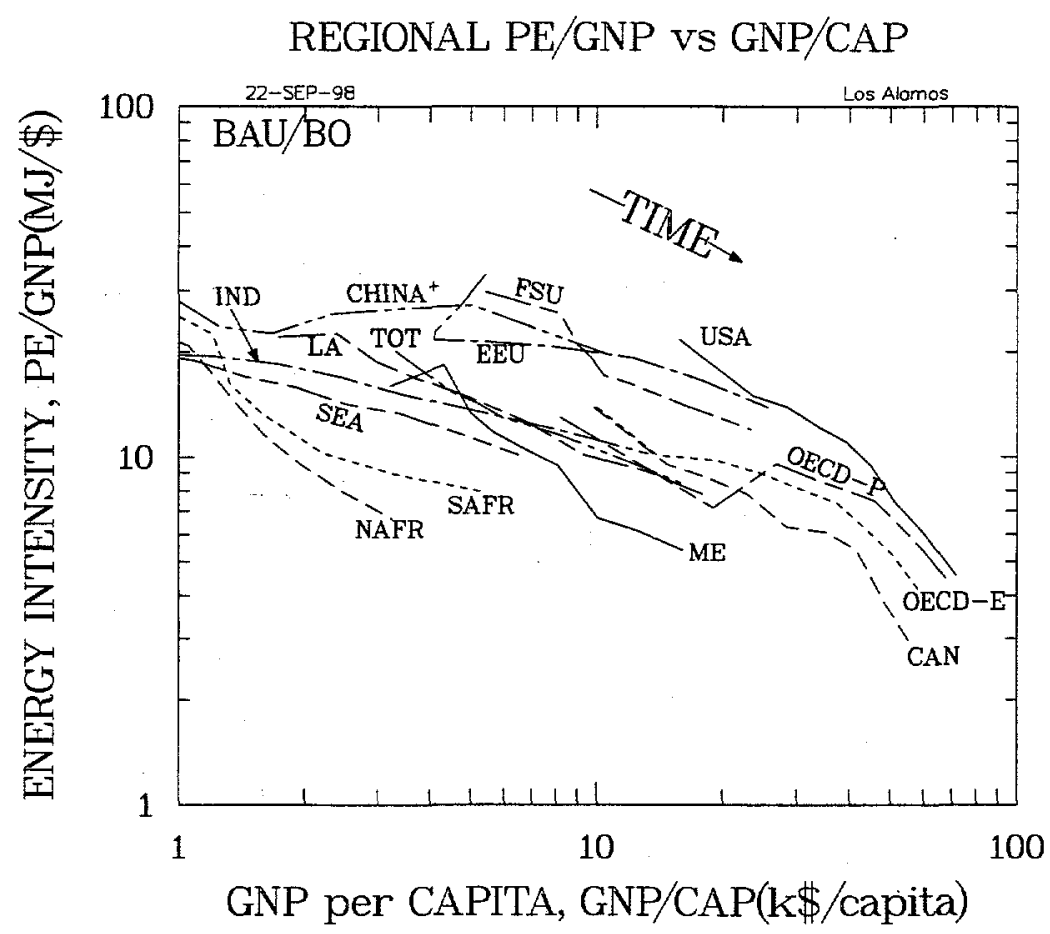

Figure 12C. Correlation of primary-energy intensity with per-capita GNP for the BAU/BO Basis Scenario for all thirteen ERB regions depicted on Fig. 5.

The World primary-energy demand for the BAU/BO Basis Scenario (Fig. 9) is shown in Fig. 13 and compared to projections made by a recently completed IAEA study ${ }^{8}$, which has as a basis the IIASA/WEC study ${ }^{27}$. Primary-energy demand results from the GEM10R "bottom-up" (technology, process) global E $\mathrm{E}^{3}$ model ${ }^{26,28,+}$ are also shown. The curve labeled "GEM10R" reflects a regional final-energy demand taken as input from the ERB model, whereas these input demands were generated by a separate SEI algorithm for the curve labeled "GEM10R*". The ERB results correspond closely to the IAEA/MV (Medium-Variant) scenario ${ }^{8}$, with the two GEM10R cases bracketing the ERB result. The World demand for nuclear energy under BAU/BO Basis-Scenario conditions is shown on Fig. 14, with regional aggregated demands (OECD, REF, and DEV, see caption on Fig. 5) also being shown. Again, the ERB demand projections for NE track closely those reported for the Medium-Variant case, IAEA/MV, reported by the recent IAEA study ${ }^{8}$, which in turn follows closely the IIASA/WEC Scenario $\mathrm{B}^{27}$.

${ }^{+}$The Russian (Siberian Energy Institute, SEI) GEM10R model ${ }^{28}$ along with the Japanese (University of Tokyo) DNE21 "bottom-up" model ${ }^{29}$, combined with ERB, resulted in a tripartite computation tool used in the IAEAsponsored $\mathrm{E}^{3}$ assessment study of a range of NE scenarios for the $21^{\text {st }}$ century, as reported in Ref. 26 and 32 . 
All NE cases considered by the ERB model assume plutonium recycle in LWRs that evolves in time to a maximum MOX core fraction of $\mathrm{f}_{\text {MOX }}=0.3$ uniformly across all thirteen global regions. Figure 14 also shows the impact of a uniformly imposed once through (LWR) fuel cycle (e.g., $\left.\mathrm{f}_{\mathrm{MOX}}=0.0\right)$; the ERB model reports slightly higher NE demands for the somewhat less-expensive once-through fuel cycle. For the NE demands corresponding to BAU/BO conditions, uranium resources do not become a cost issue until the year $\sim 2100$ or after, and, for the unit costs assumed for breeder reactors (50\% more expensive than LWRs), breeder reactors do not become competitive by the end of the $21^{\text {st }}$ Century. This situation can change under conditions where NE demand is enhance by more expensive fossil fuels (e.g., scenario $\mathrm{ED} / \mathrm{BO}$, wherein carbon taxes are imposed, and the demand for non-carbon primary-energy sources like nuclear increases.), and/or a more expensive uranium resource base is assumed. Lastly, regional NE demands for the BAU/BO Basis Scenario are shown in Fig. 14B, with EEU and CHINA ${ }^{+}$becoming major producer of nuclear energy after the years $\sim 2070$ and 2085, respectively, for the BAU/BO Basis Scenario conditions. As is shown in Ref. 26, however, the relative (dominant) NE roles between China and India are reversed under ED/BO scenario conditions; China exceeds and becomes the dominant user of NE over India in the case where fossil energy (mainly coal) is subject to a carbon tax.

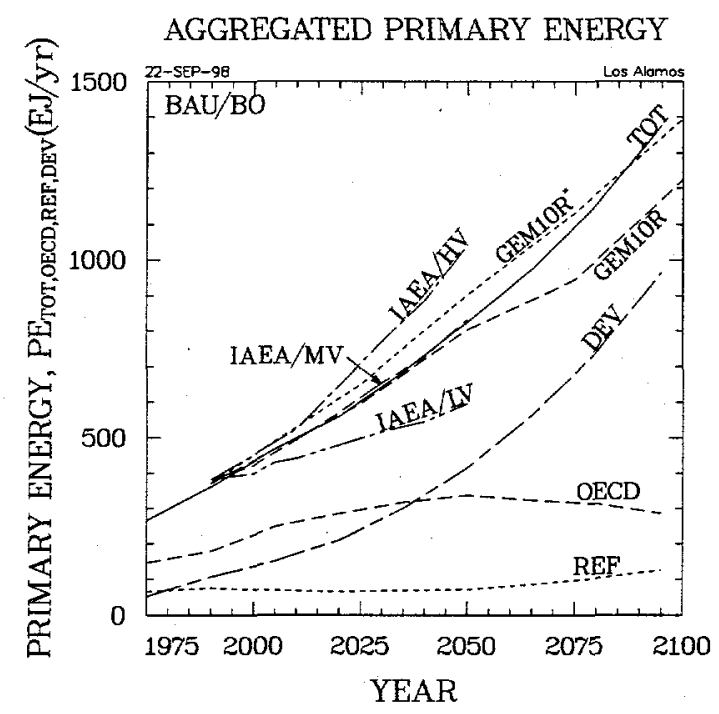

Figure 13. World primary-energy demand for the BAU/BO Basis Scenario, also showing total world (TOT), OECD, Reforming Economies (REF = FSU + EEU), and Developing (DEV) countries; comparisons are made with recent IAEA high (HV), medium (MV), and low (LV) variant projections ${ }^{8}$, which are based on the IIASA/WEC study ${ }^{27}$; the results from the GEM1OR ${ }^{26,28}$ model under BAU/BO conditions are also shown, wherein the curve labeled GEM10R uses a combination of final-secondary-energy demands from ERB as input to the GEM10R model, whereas the curve labeled GEM10R* uses a final-energy demand generated from an SEI algorithm. 


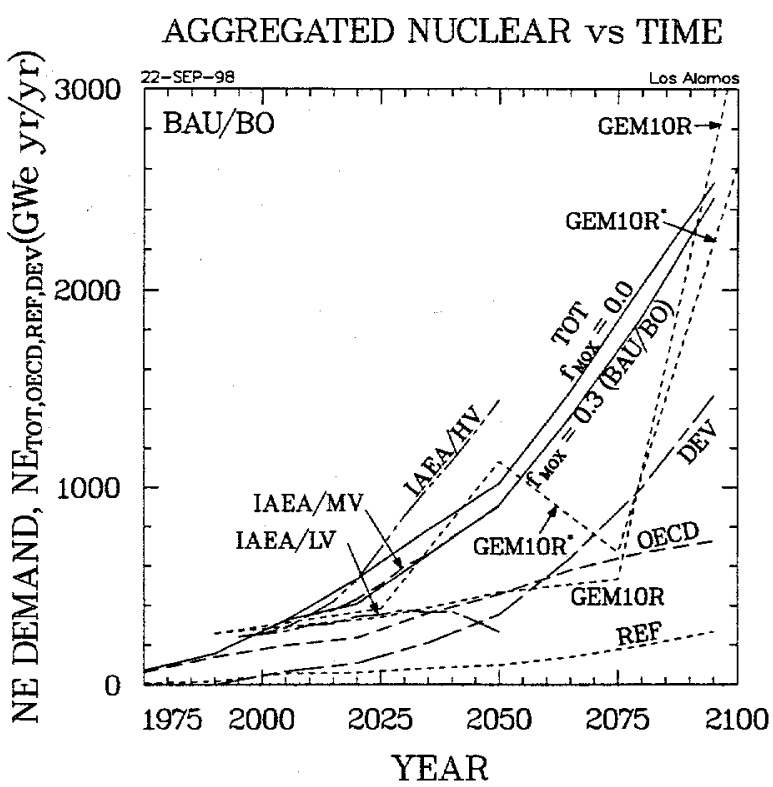

Figure 14A. World nuclear-energy demand for the BAU/BO Basis Scenario, also showing total world (TOT), OECD, Reforming Economies (REF = FSU + EEU), and Developing (DEV) countries; comparisons are made with recent IAEA high (HV), medium (MV), and low (LV) variant projections ${ }^{8}$, which are based on the IIASA/WEC study ${ }^{27}$; the results from the GEM1OR model ${ }^{26,28}$ under BAU/BO conditions are also shown, wherein the curve labeled GEM10R uses a combination of final-secondary-energy demands from ERB as input to the GEM10R model, whereas the curve labeled GEM10R* uses a final-energy demand generated from an SEI algorithm. Two values of reactor core volume used to recycle plutonium, $\mathrm{f}_{\text {MOX }}$, are indicated for the ERB results; all scenarios reported from ERB are based on the $\mathrm{f}_{\text {MOX }}=0.3$ case.

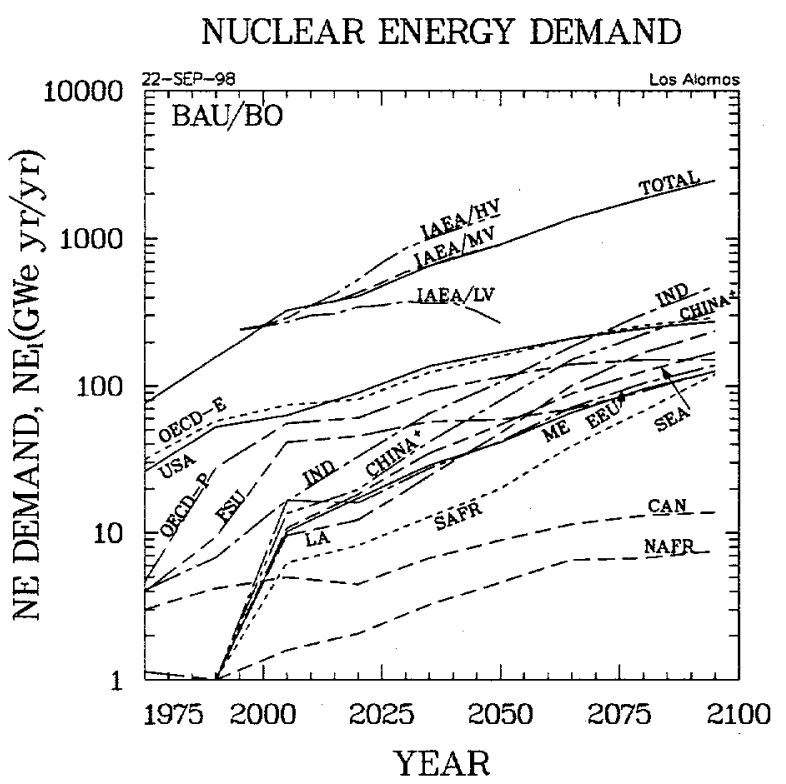

Figure 14B. Regional breakdown of nuclear-energy demand for the BAU/BO Basis Scenario, showing comparisons with recent IAEA high (HV), medium (MV), and low (LV) variant projections ${ }^{8}$, which are based on the IIASA/WEC study ${ }^{27}$. 
The NE model that is evaluated "under" ERB approximates a regionally dependent fuel cycle that tracks plutonium inventories in four aggregated categories: a) spent-fuel plutonium that has only been irradiated once in an LWR (ACC $=$ accumulated plutonium); b) spent-fuel plutonium that has as experienced $\mathrm{N}_{\mathrm{CYC}}=3$ recycles in an LWR ( $R E C=$ fully recycled, no longer usable in an thermal-spectrum reactor); b) plutonium actively undergoing fission in a reactor (REA); and d) separated plutonium either in reprocessing (REP) or in fuel fabrication $(\mathrm{FF}, \mathrm{SEP}=\mathrm{REP}+\mathrm{FF})$. Figure 15A gives the evolution of world inventories of these four forms of plutonium for conditions of a globally uniform fuel cycle (e.g., MOX recycle introduced at a rate the ultimately occupies on average a fraction $\mathrm{f}_{\text {MOX }}=0.3$ of the LWR core). Plutonium in all spent-fuel forms is represented in Fig. 15A by SFT = ACC + REC. Each of the accumulating plutonium inventories represents a form- and region-dependent proliferation risk. This risk has been (subjectively) evaluated using multi-attribute proliferant-oriented utilities $^{4}$. The normalized $(0,1)$ average utility function, $<u>$, and a Proliferation-Risk Index, PRI, based on a discounted and normalized sum of these utilities are also shown on Fig. 15A. The global $<u>$ and PRI parameters are evaluated using weightings that reflect the perspective of the USA region, are intended only as a (scenario) relative metric, and future work is needed to attach actual magnitudes and consequences to this metric. More importantly, both $\langle\mathrm{u}\rangle$ and PRI are computed using utility functions that are constrained to the civil fuel cycle and must eventually be evaluated in comparison with potentially more attractive (non-commercial) source of fissile NM (e.g., clandestine/undeclared uranium enrichment facilities, direct dealings in NW components, etc.). Lastly, the regional accumulations of (total) plutonium are depicted in Fig. 15B for the BAU/BO Basis Scenario; this figure also illustrates the impact of a once through LWR fuel cycle $\left(\mathrm{f}_{\mathrm{MOX}}=0.0\right)$ on total World plutonium inventories.

Carbon-dioxide emissions and the potential for global warming and climate changes represent the third top-level metric reported by the ERB model. Figure 16A gives the $\mathrm{CO}_{2}$ emission rate, cumulative emissions, and atmospheric accumulations as a function of time for the BAU/BO Basis Scenario. Also shown are estimates ${ }^{24}$ of average global surface temperature rises, $\Delta \mathrm{T}$, that might result from these levels of $\mathrm{CO}_{2}$ accumulations. Like the PRI metric, the average global temperature rise is a relative or interim metric, in that actual consequences (e.g., damage or benefits to regional economies, as reflected through GDP impacts) are not recorded. Considerable work is available, however, to relate $\Delta \mathrm{T}$ to an economic impact ${ }^{30,31}$, unlike the PRI metric. The regional contributions to $\mathrm{CO}_{2}$ emissions are given in Fig. 16B. Finally, Fig. 17A gives the trade-off between accumulated global plutonium (again, for the BAU/BO Basis Scenario) and the avoided accumulation of carbon dioxide that results from the use of NE. Figure 17B gives the ratio of avoided carbon dioxide mass to accumulated (total) plutonium mass, indicating that for these BAU/BO conditions this ratio after the year 2030 
amounts to 10-13 GtonneC/ktonnePu. Expressing the accumulated plutonium in terms of a proliferation-risk index and the accumulated atmospheric carbon dioxide as a global-warming potential, the correlation between PRI and $\Delta \mathrm{T}$ for these BAU/BO Basis-Scenario conditions are depicted in the Fig.-18 results for the four scenarios depicted in Fig. 19.

GLOBAL PU AND> RISK ACCUMULATTONS

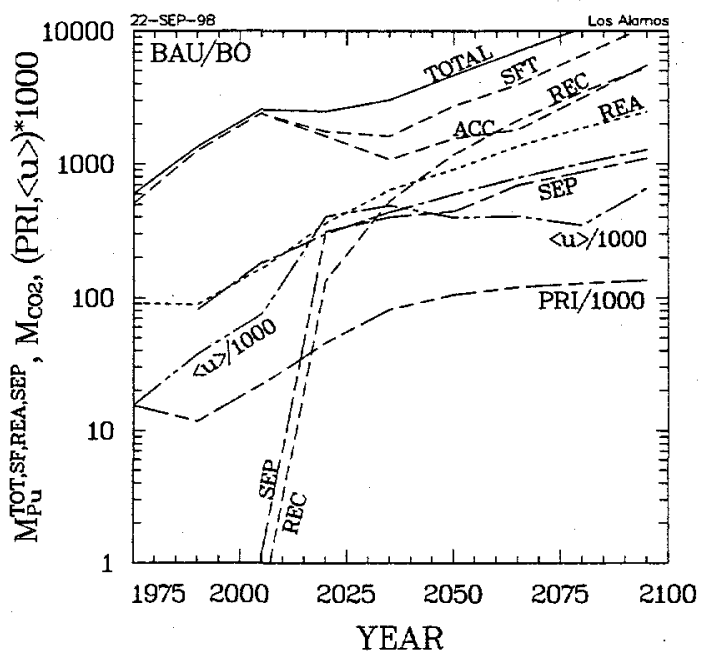

Figure 15A. Evolution of world plutonium inventories for the BAU/BO Basis Scenario, total inventory accumulations in four categories: once-exposed spent fuel, ACC; fully recycled $\left(\mathrm{N}_{\mathrm{CYC}}=3\right)$ spent fuel, REC; in-reactor plutonium, REA, and separated plutonium, SEP $=$ REP + FF; the time evolution of two (relative) proliferation metrics, $<\mathrm{u}>$ and PRI, are also show for this $\mathrm{f}_{\text {MOX }}=0.3$ Basis Scenario.

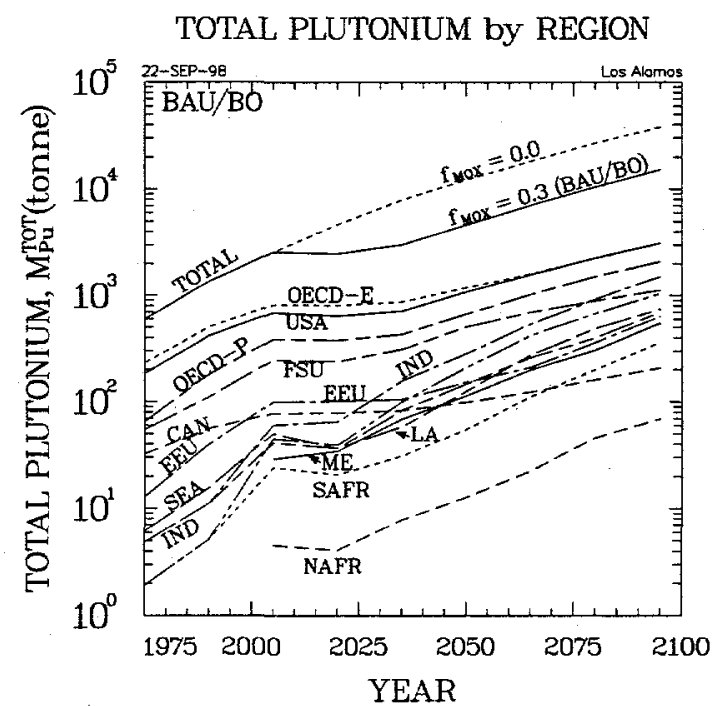

Figure 15B. Evolution of regional plutonium inventories for the BAU/BO Basis Scenario; the inventory of total plutonium for the case of a once through $\left(\mathrm{f}_{\mathrm{MOX}}=0.0\right)$ is also shown. 


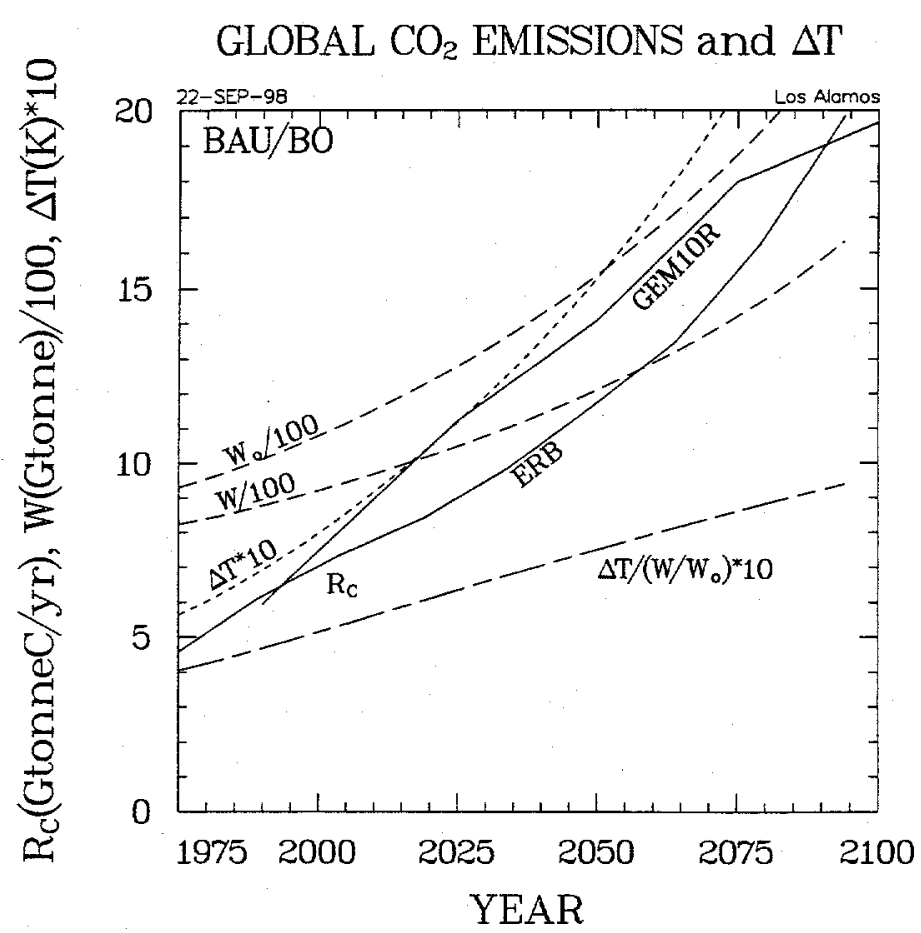

Figure 16A. Evolution of world carbon-dioxide emission rate, integrated emissions, total atmospheric accumulations ${ }^{24}$, and estimated global average temperature rise ${ }^{24}$ for the BAU/BO Basis Scenario; carbon-dioxide emission rates reported from the GEM10R model for ERB-driven BAU/BO conditions are also shown for comparison.

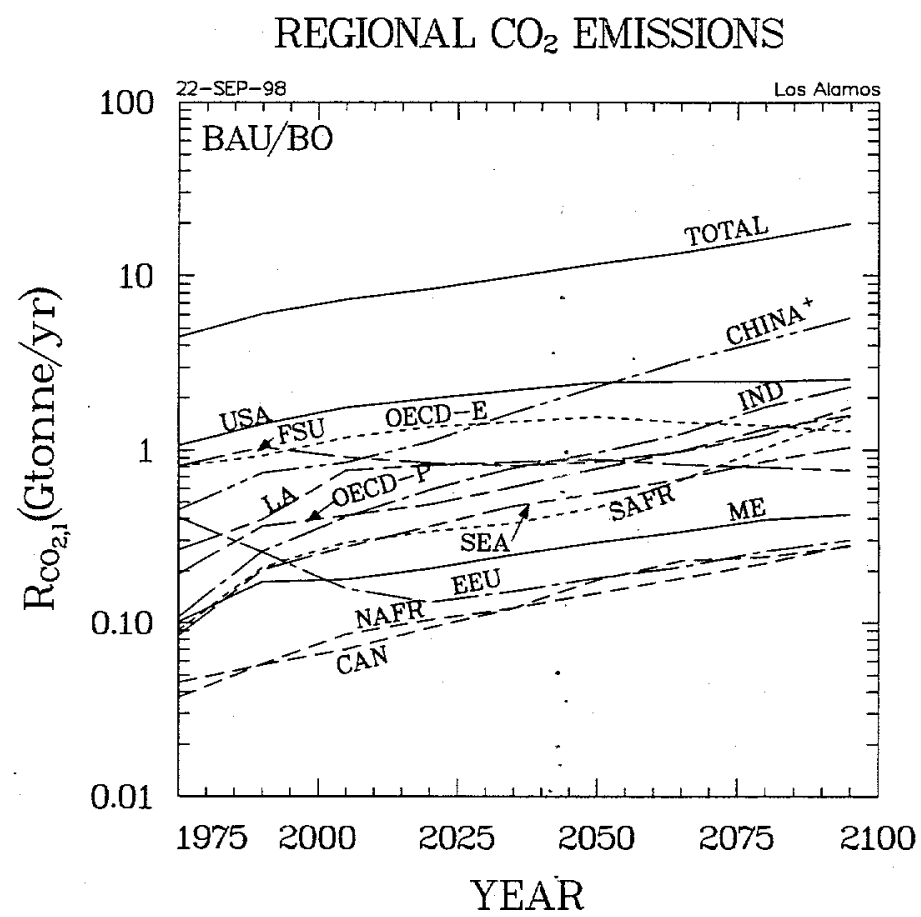

Figure 16B. Evolution of regional (Fig. 5) carbon dioxide emission rates for the BAU/BO Basis Scenario. 
GLOBAL PLUTONIUM vs AVOIDED $\mathrm{CO}_{2}$

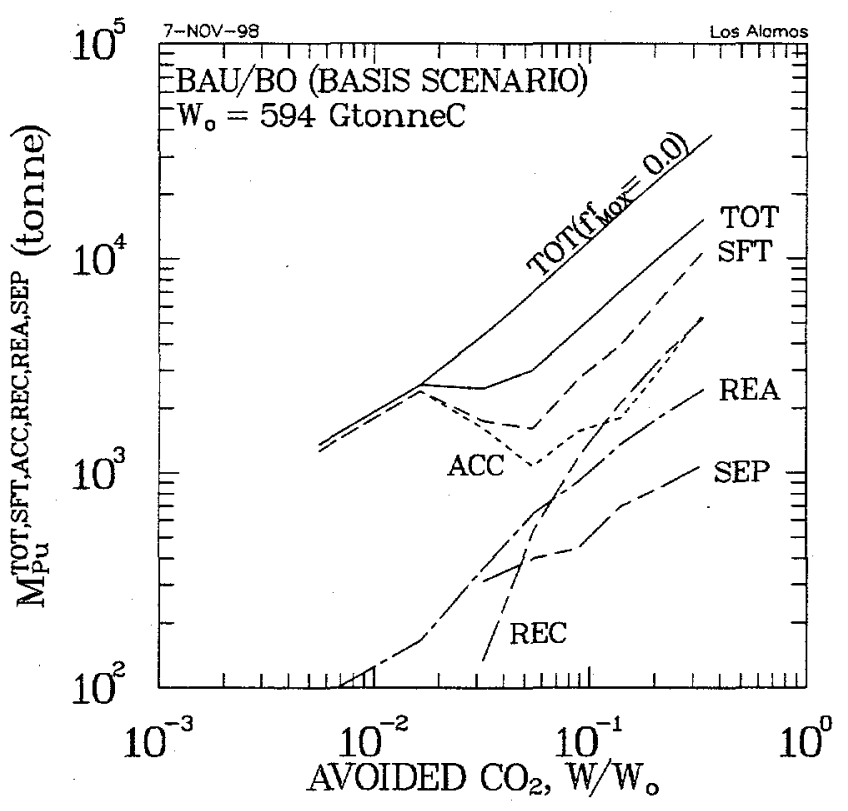

Figure 17A. Correlation of global plutonium inventory increase with $\mathrm{CO}_{2}$ avoided by the use of nuclear energy, with the four plutonium forms (SFT = ACC + REC) being shown along with the total, for the BAU/BO Basis Scenario conditions, with the normalization, $\mathrm{W}_{\mathrm{o}}$, being the atmospheric $\mathrm{CO}_{2}$ inventory at the start of the industrial revolution ( 1800); total plutonium inventory for the OT/LWR case $\left(f_{M O X}=0.0\right)$ under BAU/BO Basis Scenario conditions is also shown.

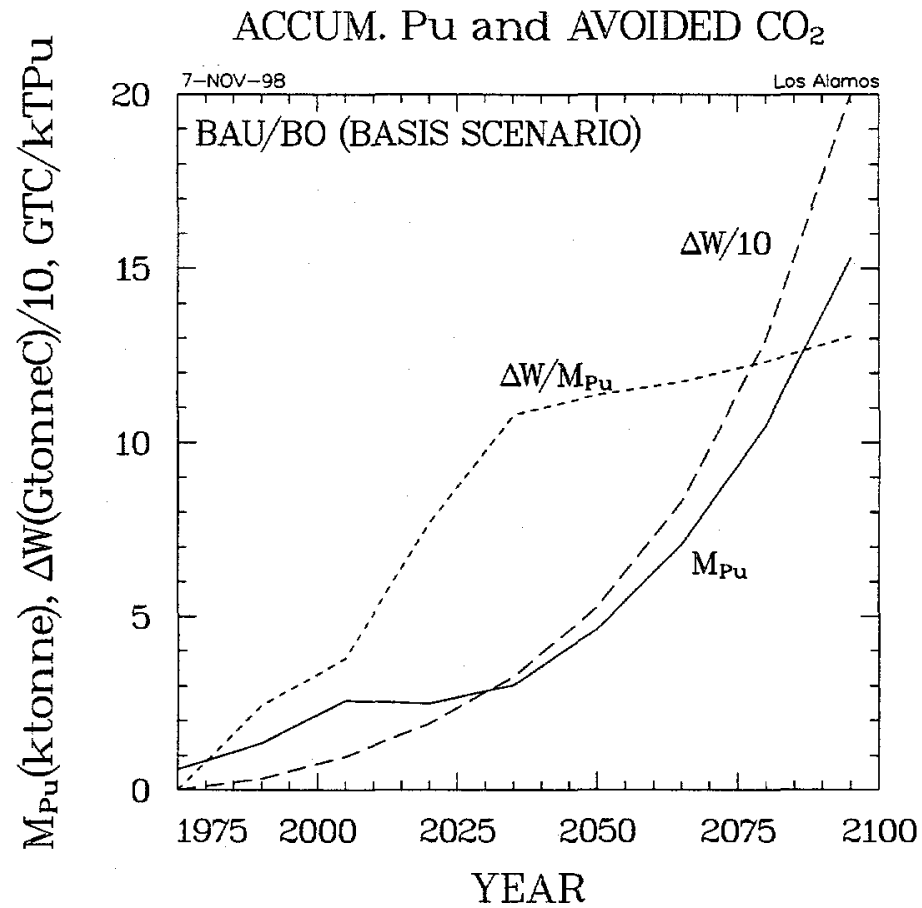

Figure 17B. Total accumulated plutonium and avoided atmospheric $\mathrm{CO}_{2}$ as a function of time for the BAU/BO Basis Scenario 
PRI vs $\Delta \mathrm{T}$

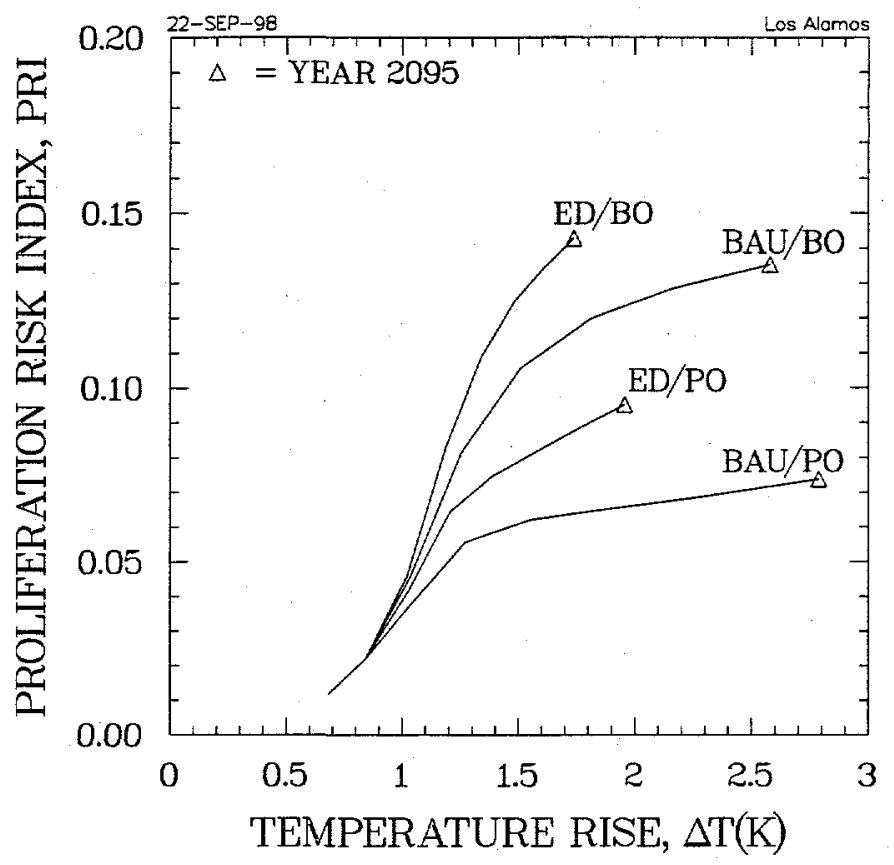

Figure 18. Correlation of proliferation-risk index with global-averaged surface temperature rise for $\mathrm{BAU} / \mathrm{BO}, \mathrm{BAU} / \mathrm{PO}, \mathrm{ED} / \mathrm{BO}$, and $\mathrm{ED} / \mathrm{PO}$ scenarios.

\section{Summary Conclusions and Future Work}

The most integrated application of the Integrated Global Energy Model was (is) as a tripartite modeling effort described in Refs. 32 and 36. This study of NE futures was conducted in collaboration with the IAEA and consisted of the "top-down" (macroeconomic) ERB model providing regional and temporal final energy demands to the GEM $10 \mathrm{R}^{28}$ and DNE21 29 "bottom-up" (technology, process) models to examine a range of NE futures. Figure 19 illustrates the four scenarios considered by this IAEA E ${ }^{3}$ Study, and Fig. 20 illustrates the inter-model organization and information flows. A synoptic comparison of the three models that comprise the IAEA $E^{3}$ Study is given in Table II. The BAU/BO scenario has been described and reported herein. The BAU/PO scenario decreases the NE market share by increasing capital cost; the ED/BO scenario increases the cost of FE through the application of a carbon tax under $\mathrm{BO}$ conditions for $\mathrm{NE}$; and the EP/PO scenario combines a carbon tax for $\mathrm{FE}$ with increased capital cost for NE. 


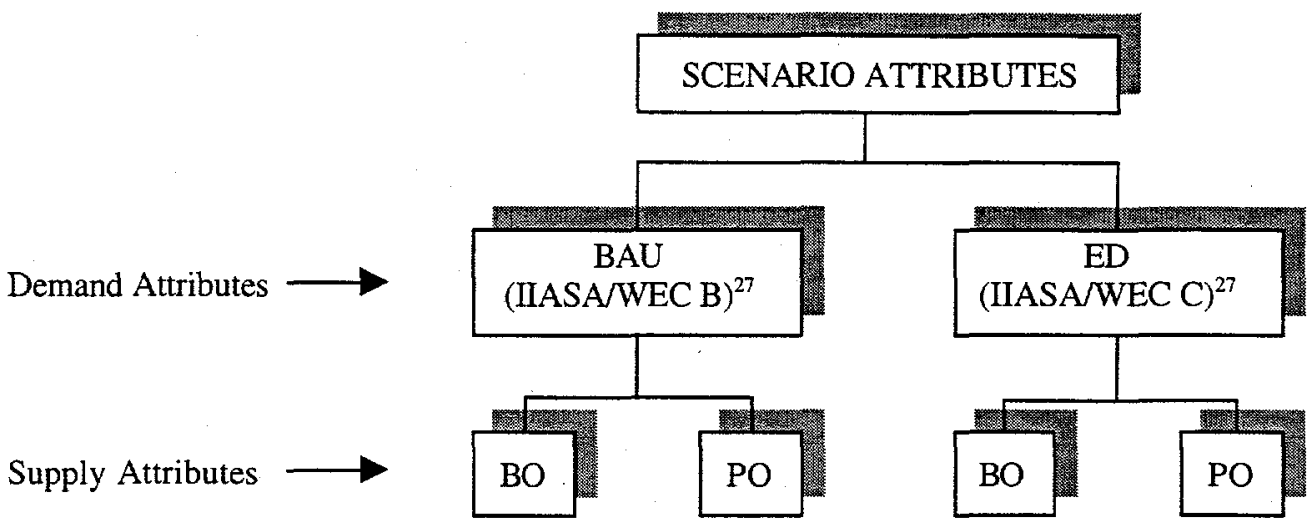

Figure 19. Combination of energy demand-side and supply-side attributes used in defining four scenarios to be investigated by IAEA E ${ }^{3}$ Study Team $^{26,32}$.

The key results generated by the ERB model have been reported in Ref. 26 according to the following grouping: a) Basis Scenario (BAU/BO); b) NE cost impacts; c) carbon-tax impacts; d) scenario inter-comparisons; and e) a range of added comparison/parametric studies, including: parametric NE-cost summary, parametric carbon-tax summary, NE potential for GHG mitigation, Fossil Energy database (FEB) impacts, and AEEI impacts for the Basis Scenario. Comments that are specific to each of these parametric grouping have been reported in the respective sections in Ref. 26 and are not repeated here. The primary intent of these parametric variations is to illustrate the quantitative sensitivity of the market drivers used to generated the BAU $\rightarrow \mathrm{ED}$ (carbon tax) and $\mathrm{BO} \rightarrow$ PO (NE capital cost) scenario transitions. Top-level conclusions based primarily on these ERB-based parametric studies are collected below and have been submitted as input to the final IAEA assessment report ${ }^{32}$ based on the inter-comparison of all three modeling approaches used in the IAEA $E^{3}$ Study. In this regard, the following ERB-specific conclusions derive:

- $B A U \rightarrow E D$ via Carbon Taxation: Stabilization of $\mathrm{CO}_{2}$ emission rates to $\sim 1990$ levels requires carbon taxes to be increased at a linear rate of CTAX $=30 \$ /$ tonneC/15yr; this level of carbon tax increases World NE demand in the year 2095 from $2.47 \mathrm{TWeyr} / \mathrm{yr}$ (BAU/BO) to $3.91 \mathrm{TWeyr} / \mathrm{yr}$ (ED/BO), or an increase of $58 \%$ relative to the $\mathrm{BAU} / \mathrm{BO}$ Basis Scenario.

- $B O \rightarrow P O$ via NE Cost Increase: A gradual ( 40 year) increase in NE capital cost over the $\mathrm{BAU} / \mathrm{BO}$ conditions of a factor in excess of three is required to induce a reduction in NE demand in the year 2095 by a factor in excess of 20 , using the logit-based market-share paradigm that forms the basis of the ERB model; even at very high NE capital costs, the highly diminished NE demand shows slow growth in later years, as resource-driven 
increases in fossil energy cost arise. The sensitivity of NE demand to capital cost indicates an "elasticity" of $\sim 2.5$, as shown in Fig. 21.

- $B A U / P O \rightarrow E D / P O$ via Carbon Taxation: The logit-based market-share paradigm used in the ERB model cause the diminished NE demands for the ED/PO scenario rise above that for the BAU/PO case, albeit, both are greater than an order of magnitude below those for either BO case as is illustrated in Fig. 22.

- Plutonium-GHG Linkage: While both inventories of civil plutonium and atmospheric $\mathrm{CO}_{2}$ grow in time, as illustrated in Fig. 18, the relative accumulations of these two materials and the potential risks each embodies (e.g., nuclear proliferation versus GCC) vary greatly among the scenarios considered; for the LWR/MOX fuel cycle adopted, each Gtonne of atmospheric carbon avoided by $\mathrm{NE}$ is accompanied by an addition of one ktonnePu (of all forms) to global plutonium inventory (Fig. 17B); relative economic, GCC, and proliferation-risk trade offs exist for NE, as is shown in Fig. 23, and for FE in Fig. 24, as respective costs shift.

- Fossil-Energy Resource Data Base (FEB): Relatively significant changes in FEB assumptions (e.g., limited/costly ${ }^{2}$ to less-limited/less-costly $\left.{ }^{23}\right)$ has only minor $(\sim \pm 10 \%)$ impacts on global PE and NE demand for the BAU/BO Basis Scenario; the impact on the latter is equivalent to adopting the somewhat less-expensive LWR/OT fuel cycle; the impact of FEB assumption on PE demand and $\mathrm{CO}_{2}$ emission, while small (again $10 \%$ ), varies in sign and magnitude with time.

- BAU/BO, ED/BO, and Other Scenarios: The NE demands for the BAU/BO Basis Scenario tracks closely the Medium-Variant scenario reported by the recent IAEA study ${ }^{8}$ (Fig. 14A), and the enhanced NE demand for the ED/BO scenario tracks closely the High-Variant IAEA scenario ${ }^{8}$. In both cases China and India become dominant NE regions, but their respective positions shift as coal is more heavily taxed.

- Role of $\mathrm{NE}$ in Mitigating $\mathrm{CO}_{2}$ Emissions: Approximately 20-25\% of $\mathrm{CO}_{2}$ emissions are associated with electricity generation, as is shown in Figs. 25A and 25B. The contribution of $\mathrm{NE}$ in mitigating $\mathrm{CO}_{2}$ emissions is small for the $\mathrm{BAU} / \mathrm{BO}$ scenario; this contribution amounts to almost $\sim 24 \%$ by the year 2095 (Fig. 25), but this role increases for the ED/BO scenario ( $90 \%$ by the year 2095). A preliminary correlation of decreased global temperature rise in the year 2095 with increased utilization of nuclear power induced through the imposition of a carbon tax has been estimated and reported in Fig. 26A; this supply-side mitigation approach compares with the demand-side tact related to the rate at which $\mathrm{SE} \rightarrow$ FE conversion efficiency improves with time, $\varepsilon_{k}(1 / \mathrm{yr})$; these demand-side impacts are also illustrated in Fig. 25A. Nuclear energy can play a greater role in mitigating $\mathrm{CO}_{2}$ emissions 
only if: a) electricity end-use is increased and/or; b) the application of NE expands to accommodate non-electric demands.

- $\mathrm{CO}_{2}$ versus Plutonium: The ratio of $\mathrm{NE}$-avoided $\mathrm{CO}_{2}$ to total accumulated civil plutonium by the year 2095 is $13 \mathrm{GtonneC} / \mathrm{ktonnePu}$ for the BAU/BO scenario (and slowly increasing, Fig. 17B) and $10 \mathrm{GtonneC/ktonnePu}$ for the ED/BO scenario (and slowly decreasing). This ratio is based on a worldwide LWR/MOX ( $f_{M O X}=0.3$ ) fuel cycle; this ratio can be increased, depending on details of the fuel cycle adopted (e.g., use of LWR/FSB fuel cycle). The direct correlation between accumulated $\mathrm{CO}_{2}$ and accumulated (total) plutonium, and between the related $\Delta \mathrm{T}$ and PRI metrics in the year 2095 as the carbon tax rate varies is shown in Fig. 26B; the percentage change in proliferation-related metrics (relative to the zero-carbon-tax case) is stronger than linear (inverse of these "elasticities" shown in Fig. 26B) with the decrease in the GCC metric relative to the zerocarbon tax case. It remains as future work to assess the relative risks of accumulated $\mathrm{CO}_{2}$ versus accumulated $\mathrm{Pu}$, as well as the relative efficacy of mitigating $\mathrm{CO}_{2}$ emissions through use of other non-carbon energy options applied to the supply-side or increased efficiency applied to the demand-side.

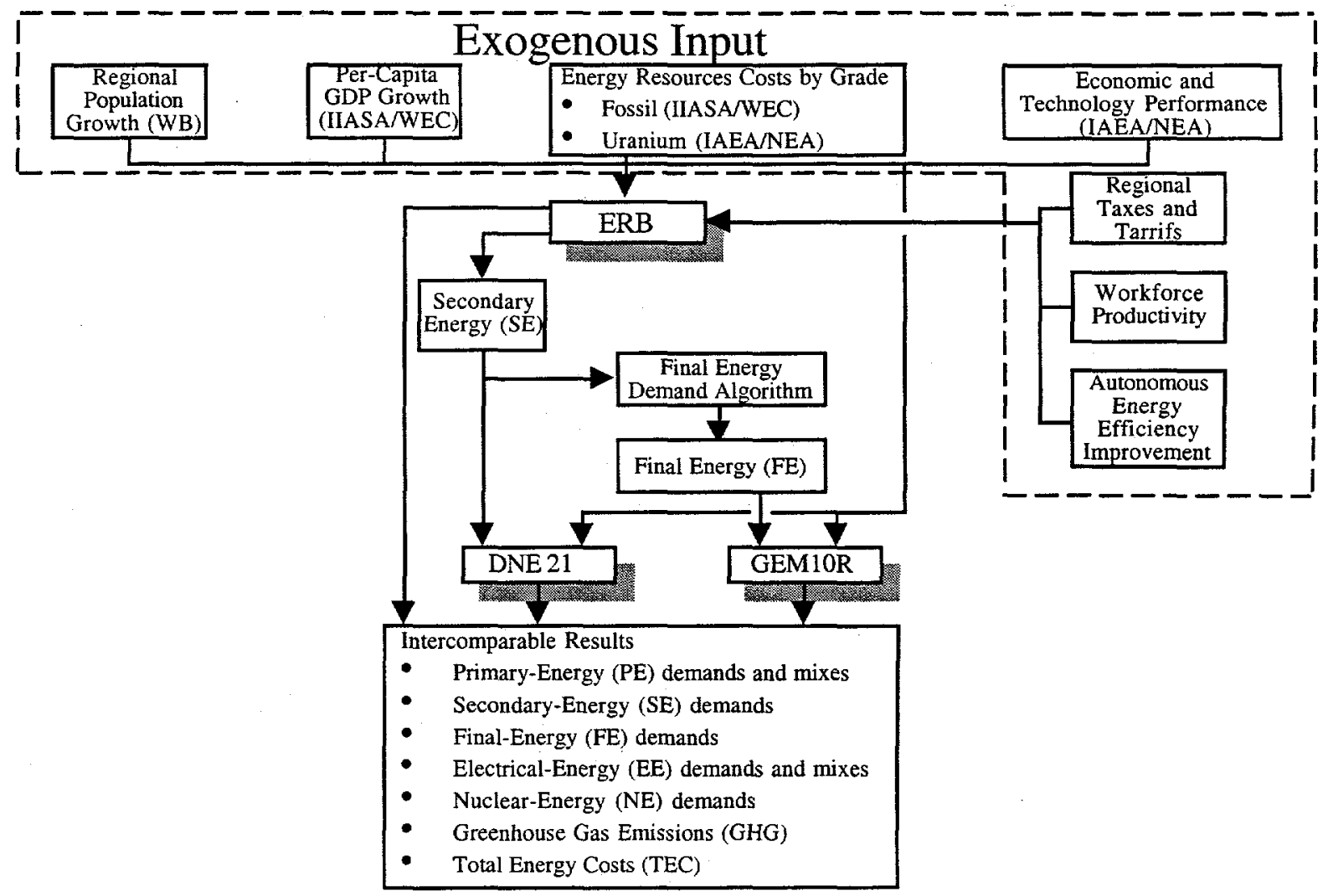

Figure 20: Information flow between "top-down" ERB model ${ }^{2,3,5}$ and "bottom-up" DNE21 model $^{29}$ and GEM10R model ${ }^{28}$, showing shared exogenous inputs and key intercomparable results. 


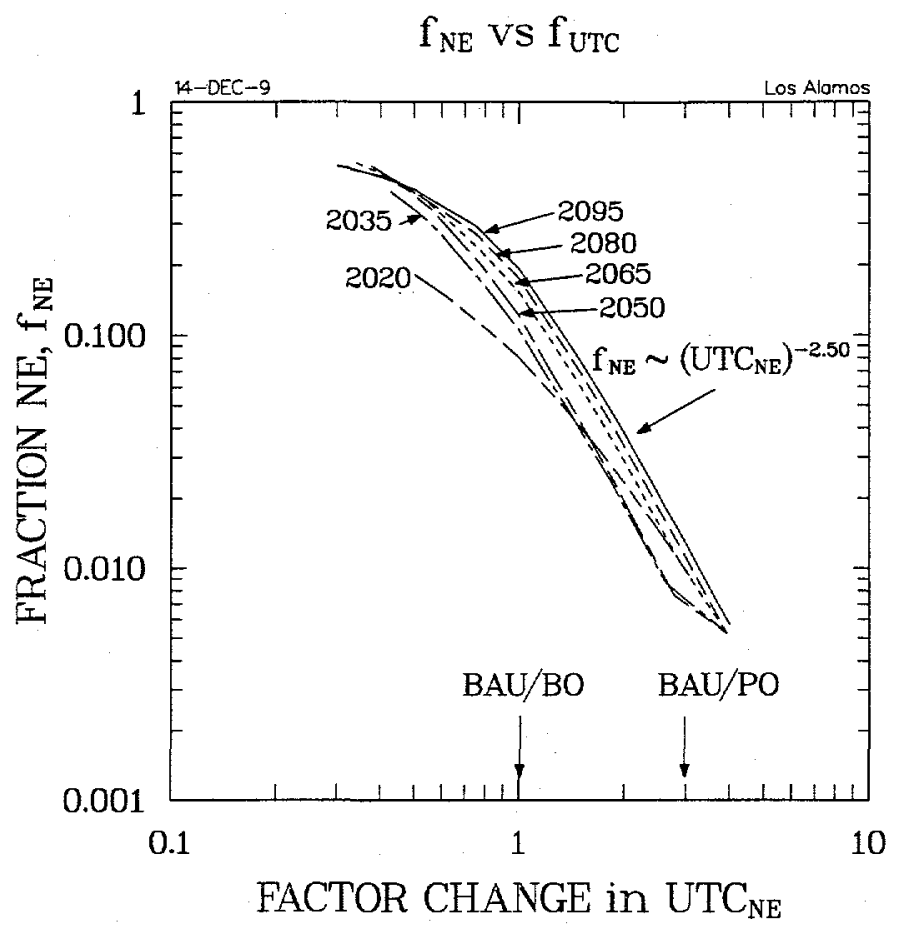

Figure 21. Change in NE demand as a fraction of total $\mathrm{PE}, \mathrm{f}_{\mathrm{NE}}$, as a function of factor change in unit total costs, $\mathrm{f}_{\mathrm{UTC}}^{\mathrm{f}}$, for a range of times; an effective "elasticity" is shown.

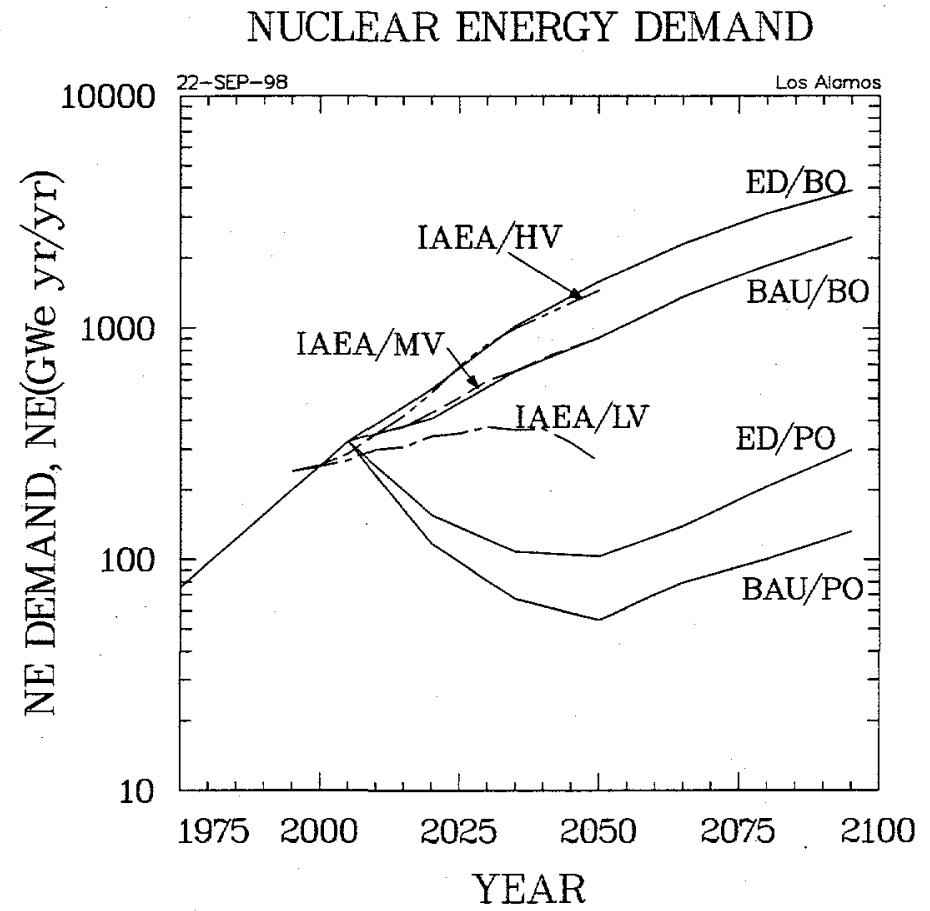

Figure 22. World nuclear energy demand for the BAU/BO Basis Scenario, along with comparable plots for the $\mathrm{BAU} / \mathrm{PO}, \mathrm{ED} / \mathrm{BO}$, and $\mathrm{ED} / \mathrm{PO}$ scenarios; comparisons are made with recent IAEA high (HV), medium (MV), and low (LV) variant projections $^{8}$, which are based on the IIASA/WEC study ${ }^{11}$. 
UTC $_{\text {NE }}$ PERCENTAGE IMPACTS

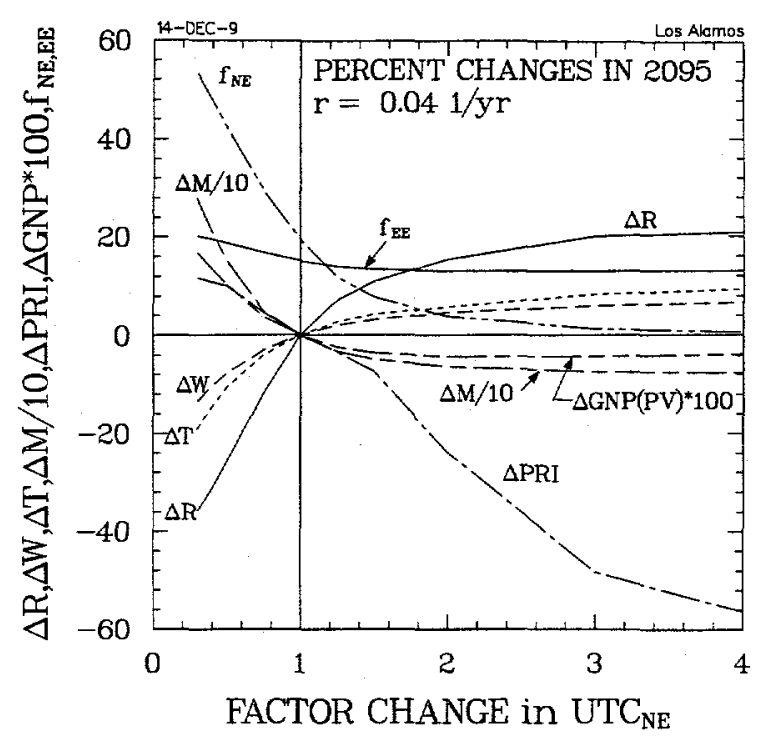

Figure 23. Summary of relative sensitivities of key metrics to NE capital-cost variations, as induced through the parameter $\mathrm{f}_{\mathrm{UTC}}^{\mathrm{f}}$ [Eq. (1)], measure in 2095 and referenced to the BAU/BO $\left(\mathrm{f}_{\mathrm{UTC}}^{\mathrm{f}}=1.0, \mathrm{CTAX}=0.0 \$ /\right.$ tonneC/yr) Basis Scenario in the year 2095; Table III. gives values used to perform the normalizations, as well as key definitions.

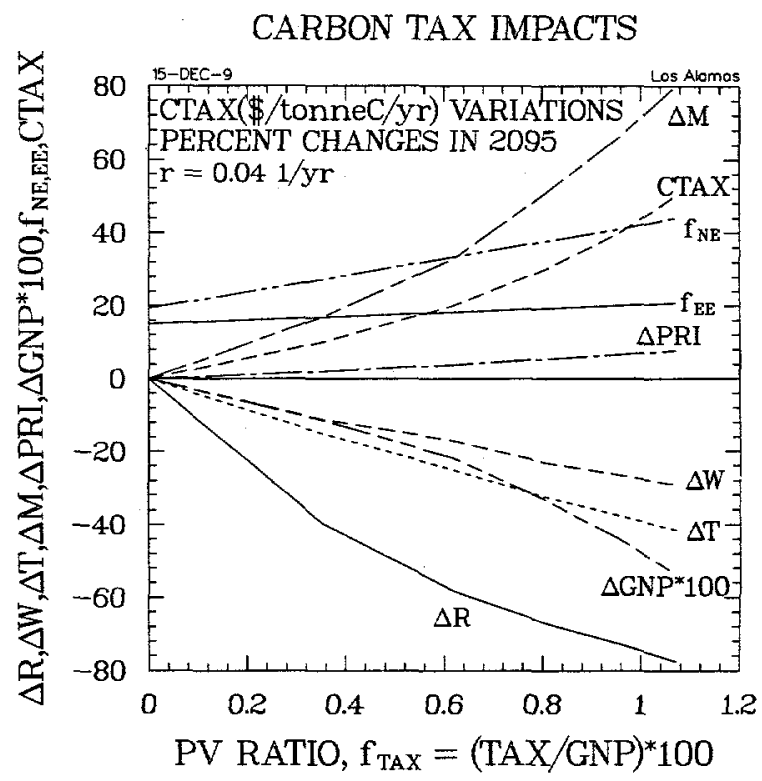

Figure 24. Summary of relative sensitivities of key metrics to (linear) carbon taxation, with the ratio of present-value of total carbon taxes to the present-value of gross world product, $\mathrm{f}_{\text {TAX }}$, being used to express the impact of a range of (linear) carbon-tax rates, CTAX (\$/tonneC/15yr), and with metrics measure in 2095 and referenced to the BAU/BO $\left(\mathrm{f}_{\mathrm{UTC}}^{\mathrm{f}}=1.0, \mathrm{CTAX}=0.0 \$ /\right.$ tonneC/yr) Basis Scenario in the year 2095; Table III. gives values used to perform the normalizations, as well as key definitions. 


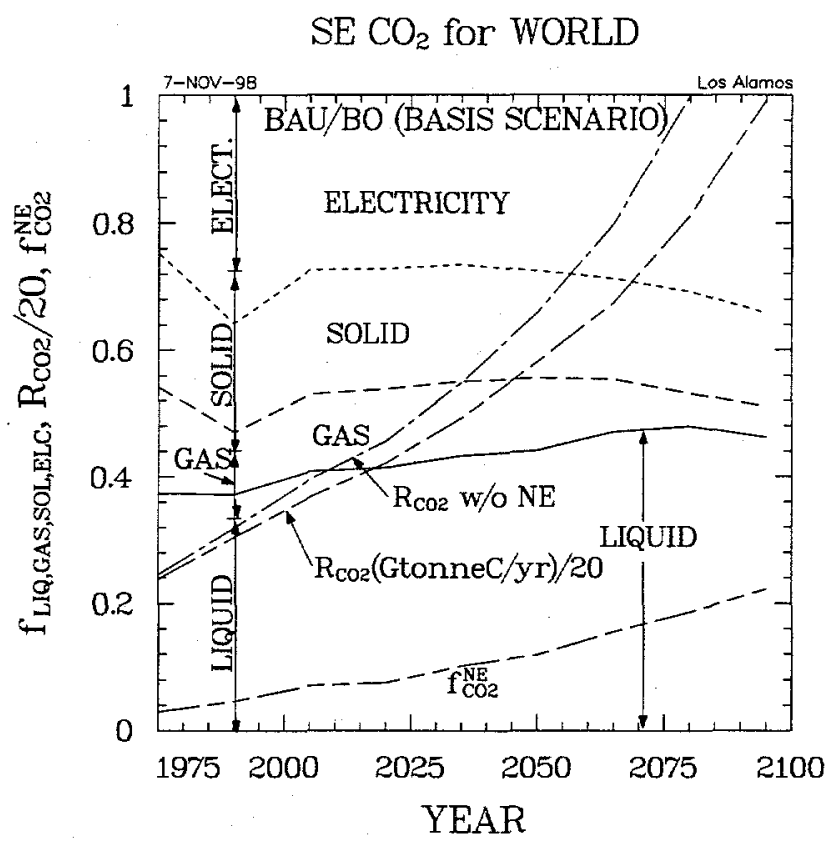

Figure 25A. Time-dependent fraction of global $\mathrm{CO}_{2}$ emissions attributed to each of four secondary energy (SE) categories for the BAU/BO Basis Scenario; also shown are the rates of $\mathrm{CO}_{2}$ emissions, $\mathrm{R}_{\mathrm{CO}_{2}}$, for both $\mathrm{BAU} / \mathrm{BO}$ conditions and if $\mathrm{NE}$ demand were replaced with the average $\mathrm{FE}$ mix existing at that time; the fraction reduction on $\mathrm{CO}_{2}$ attributable to $\mathrm{NE}, \mathrm{f}_{\mathrm{CO}_{2}}^{\mathrm{NE}}$, is also shown.

$\mathrm{FE} \mathrm{CO}_{2}$ for WORLD

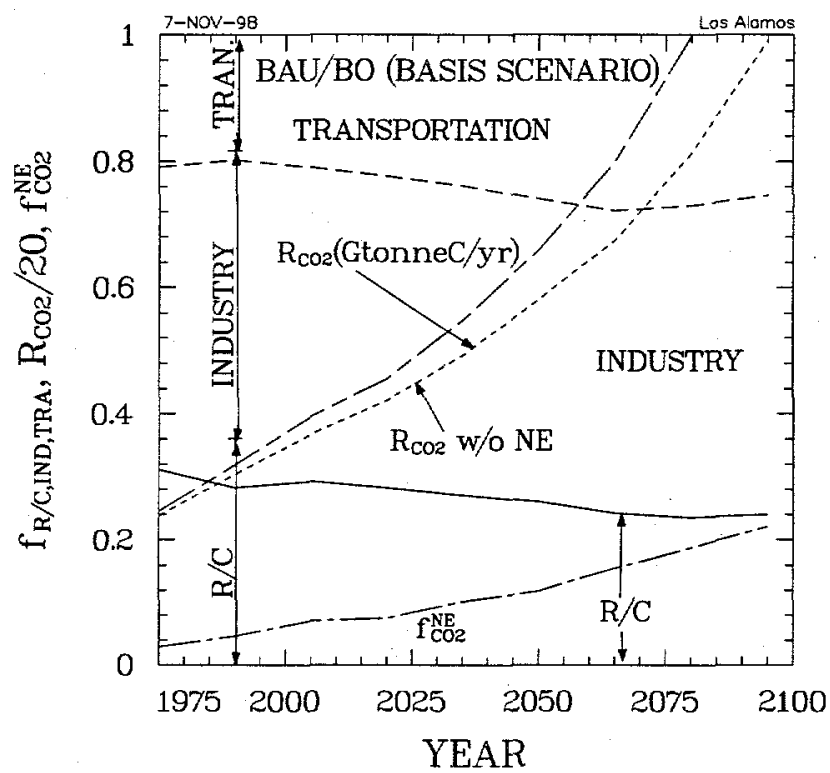

Figure 25B. Time-dependent fraction of global $\mathrm{CO}_{2}$ emissions attributed to each of three final energy (FE) categories for the BAU/BO Basis Scenario; also shown are the rates of $\mathrm{CO}_{2}$ emissions, $\mathrm{R}_{\mathrm{CO}_{2}}$, for both $\mathrm{BAU} / \mathrm{BO}$ conditions and if $\mathrm{NE}$ demand were replaced with the average $\mathrm{FE}$ mix existing at that time; the fraction reduction on $\mathrm{CO}_{2}$ attributable to $\mathrm{NE}, \mathrm{f}_{\mathrm{CO}_{2}}^{\mathrm{NE}}$, is also shown. 
PRI and $\Delta \mathrm{T}$ vs NE for 2095

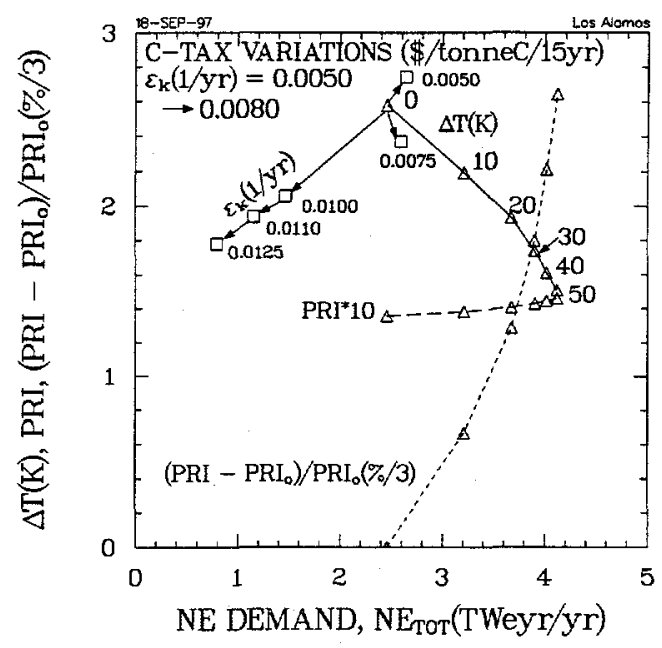

Figure 26A: Correlation of decreased global temperature rise in the year 2095 with increased utilization of nuclear power induced through imposition of a carbon tax starting in the year 2005 with the indicated constant rate CTAX(\$/tonneC/15yr). Also shown is the corresponding increase in absolute and relative (to the BAU/BO Basis Scenario) PRI. The impact of changing the rate at which $\mathrm{SE} \rightarrow \mathrm{FE}$ conversion efficiency improves with time, $\varepsilon_{k}(1 / \mathrm{yr})$ is also shown; the BAU/BO Basis Scenario assumes $\varepsilon_{\mathrm{k}}$ is constant at $0.0051 / \mathrm{yr}$ up to the year 2005 , and then linearly increases to $0.0081 / \mathrm{yr}$ by 2095 .

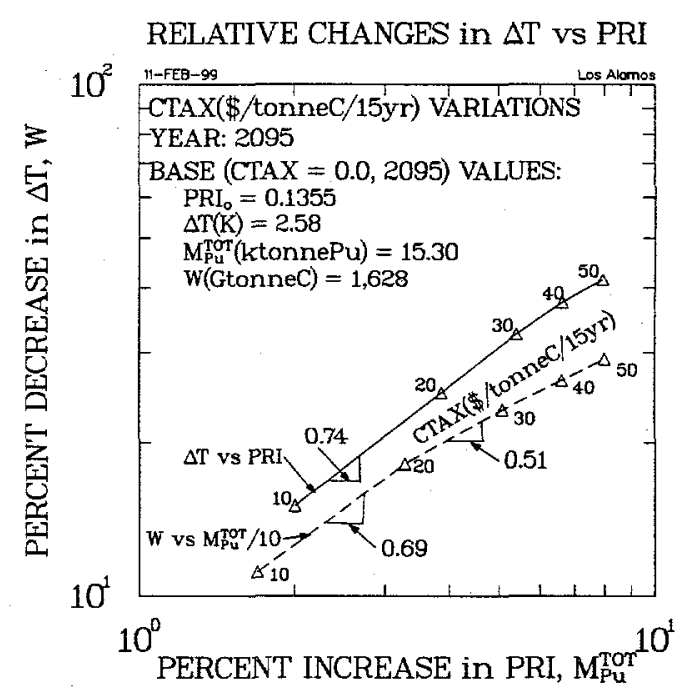

Figure 26B: Correlation between accumulated $\mathrm{CO}_{2}$ and total plutonium and between the related $\Delta \mathrm{T}$ and PRI metrics in the year 2095 as the carbon tax rate is varied. The "elasticity" for the $\mathrm{W}-\mathrm{M}_{\mathrm{Pu}}^{\mathrm{TOT}}$ relationship varies between 0.51 and 0.69 , and that for the $\triangle \mathrm{T}$-PRI relationship is 0.74 over the full CTAX range. Hence, the percentage change in proliferation-related metrics (relative to the zero-carbon-tax case, $\mathrm{M}_{\mathrm{Pu}}^{\mathrm{TOT}}$ or PRI, is stronger than linear (inverse of these "elasticities") with the decrease in the GCC metric, $\mathrm{W}$ or $\Delta \mathrm{T}$, relative to the zero-carbon tax case. 
These interim conclusions/findings derive from a highly aggregated model of global energy-economic interactions. This aggregation is reflected in both the costing algorithms used to feed unit NE costs ( $\$ / G J)$ as input to the ERB market-share algorithm and in the nuclearmaterials (NM) flow and inventory algorithm used to evaluate the nuclear-proliferation models. Shortcomings related to both model aggregations and to simplifications define the agenda for future work on this "top-down" (macroeconomic) approach to understanding $\mathrm{E}^{3}$ interactions; key elements of this research agenda include:

- Nuclear Costing: Attempts to fit "bottom-up" features in the costing of NE to the generically "top-down" ERB model need expansion to include more detail in both the fuelcycle and the capital-cost inputs to the composite unit cost of energy ( $\$ / G J)$ used ultimately to determine NE market share, and related proliferation versus GCC trade offs; central to improving fuel-cycle costing algorithms is the need to choose regional and temporal plutonium recycle options based on economic (including the costs associated with a given proliferation risk associated with the NE fuel cycle) considerations, rather than on the basis of a (region-dependent) exogenous driver.

- Nuclear Materials Flows and Inventories: While (regional) resolution into ACC, REC, SEP $=\mathrm{FF}+\mathrm{RP}$, and REA plutonium forms with which proliferation risks can be assessed is a start, a rule-based algorithm for inter-regional transport and accumulations base both on costs and sanctions needs development to resolve and optimize regional plutonium supply and demand under conditions where proliferation risk (including losses during transport) is minimized.

- Breeder Requirements: Integration of plutonium requirements of an evolving breeder economy vis á vis coupling regional and temporal breeding ratios to other parts of the nuclear fuel cycle is needed for any model that seriously evaluates and optimizes the potential and need for breeder reactors; this potential and need should also be evaluated against advances in sea-recovery of uranium, while simultaneously weighting the need to hold regional plutonium levels at risk-optimal levels.

- Fast Spectrum Burners: Comments made in connection with the last three items, as related to improved understanding of the short- and long-term role of FSBs in closing the nuclear fuel cycle, apply here also.

- Proliferation Metrics: The growing inventories of plutonium in the four forms described above so far are expressed only in terms of a relative metric, PRI; not only must this metric be expressed in terms that can be compared to other risks (e.g., GCC, stunted economic productivity, etc.), but sources of proliferation risk related to, but occurring outside, the civil nuclear fuel cycle must be included in the overall proliferation risk metric (e.g., HEU 
from undeclared facilities, uses of declared facilities for undeclared purposes, direct acquisition of NW components, etc.).

- Neutronics: The neutronics model used to feed the nuclear materials flows and inventories is a highly approximate description based on time-averaged reactor core isotopic; key averaged parameters used in this model need a firmer connection with more detailed neutronic computations.

- Greenhouse Warming: Modeling both the dynamics and economics of GHG-driven GCC need further advancement in relating costs of both demand-side (energy intensity, GDP/PE, decreases via the AEEI-like parameters) and supply-side (non-carbon energy sources) approaches to $\mathrm{CO}_{2}$ abatement to actual GCC-related damage costs and/or benefits; expansion of the carbon-taxation model, along with sectoral, temporal, and regional discounting procedures, need to be formulated and integrated into a global optimization of GHG abatement/mitigation paths.

- Non-Carbon Energy Sources: The primary non-carbon (NC) energy source considered in this study is NE, but NE must compete with other NC approaches to mitigating GCC; improved modeling of this competition, particularly biomass, is needed; such an improvement requires a level of attention to land-use issues that does not exist in the version of ERB presently being used. Furthermore, cost-induced decreases (phase out) of NE should result in a transfer of R\&D funds to other NC energy sources, thereby reducing their costs. 


\section{Publications}

1. Krakowski, R. A., "Global Nuclear Energy/Materials Modeling in Support of Los Alamos Nuclear Vision Project: Long-Term Tradeoffs Between Nuclear- and Fossil-Fuel Burning," Proc. Global Foundation Conference: Technology for the Global Economic, Environmental, and Survival and Prosperity, Miami Beach, FL (November 8-10, 1996), Plenum Press, New York, NY (1997) [also, Los Alamos National Laboratory document LA-UR-96-4873 (February 14, 1997).

2. Krakowski, R.A., Davidson, J. W., Bathke, C.G., Arthur, E. D., and Wagner, R. L., Jr., "Nuclear Energy and Materials in the 21st Century," Intern. Symp. on Nuclear Fuel Cycle and Reactor Strategies: Adjusting to New Realities, IAEA, Vienna (June 3-6, 1997), IAEA publication, Vienna, Austria (1998) [also, Los Alamos National Laboratory document LA-UR-97-1716 (May 7, 1997)].

3. Krakowski, R. A., and Bathke, C. G., "Reduction of Worldwide Plutonium Inventories Using Conventional Reactors and Advanced Fuels: A Systems Study," Los Alamos National Laboratory document LA-UR-97-2808 (July 17, 1997).

4. Krakowski, R. A., "Mitigation of Atmospheric Carbon Emissions Through Increased Energy Efficiency versus Increased Non-Carbon Energy Sources: A Trade Study Using a Simplified 'Market-Free' Exogenously Driven Model," Los Alamos National Laboratory document LA-UR-97-3581 (September 5, 1997).

5. Krakowski, R. A., Bathke, C. G., and Chodak, P., III, "Reduction of Worldwide Plutonium Inventories Using Conventional Reactors and Advanced Fuels: A Systems Study," Proc. Global `97 Intern. Conf. on Future Nuclear Systems, pp. 775-781, Yokohama, Japan (October 5-10, 1997).

6. Krakowski, R. A., Davidson, J. W., Bathke, C. G., Arthur, E. D., and Wagner, R. L., Jr., "Global Economic/Energy/Environmental $\left(\mathrm{E}^{3}\right)$ Modeling of Long-Term Nuclear Futures," Proc. Global '97 Intern. Conf. on Future Nuclear Systems, pp. 885-892, Yokohama, Japan (October 5-10, 1997).

7. Krakowski, R. A., and Bathke, C. G., "Long-Term Global Nuclear Energy and Fuel Cycle Strategies," Los Alamos National Laboratory document LA-UR-97-3826 (September 24, 1997).

8. Krakowski, R. A., "Long-Term Economic/Energy/Environmental $\left(\mathrm{E}^{3}\right)$ Impacts and Trade Offs of Fossil- versus Fissile-Fuel Burning," Proc. Intern. Specialists Meeting on Future Nuclear Systems and Fuel Cycle Options, pp. 29-62, Tokyo Institute of Technology, Tokyo, Japan (October 13, 1997).

9. Krakowski, R. A., "The Role of Nuclear Energy in Mitigating Greenhouse Warming,"Global Foundation Intern. Conf. on Eṇvironment and Nuclear Energy, Washington, D.C. (October 27-19, 1997), Plenum Press (1998) [also, Los Alamos National Laboratory document LA-UR-97-4891 (December 12, 1997).

10. Krakowski, R. A., "Endogenized Demographics for Use in Global Energy Modeling," Los Alamos National Laboratory document LA-UR-98-767 (February 23, 1998).

11. Krakowski, R. A., "Energy-Economics-Environment ( $\left.\mathrm{E}^{\wedge} 3\right)$ Modeling Activities/Capabilities at Los Alamos National Laboratory," USDOE Energy-Economics- 
Environment ( $\mathrm{E}^{3}$ ) Workshop, Washington D.C., (March 11-13, 1998), Los Alamos National Laboratory document LA-UR-98-945 (March 6, 1998).

12. Krakowski, R. A., "Description of ERB (Edmonds, Reilly, Barns) Global E ${ }^{3}$ (Energy, Economics, Environment) Model," Los Alamos National Laboratory document LA-UR-98-1364 (April 1, 1998).

13. Krakowski, R. A., "Re-Engineering Fission: Reactors for Safe, Globally Sustainable, Proliferation-Resistant, and Cost-Effective Nuclear Power," Workshop on Innovative Energy Systems and Carbon-Dioxide Stabilization, Aspen Global Climate Change Institute, Aspen, CO (July 14-24, 1998) [to be published 1999; also, Los Alamos National Laboratory document LA-UR-98-3768 (September 28, 1998)].

14. Krakowski, R. A., Bennett, L., and Bertel, E., "Nuclear Fission for Safe, Globally Sustainable, Proliferation-Resistant, and Cost-Effective Energy," Proceedings of Global Foundation Conference on Preparing the Ground for Renewal of Nuclear Power, Paris, France (October 22,23, 1998), Plenum Press, New York, NY [to be published 1999, also, Los Alamos National Laboratory document LA-UR-98-4292 (September 28, 1998)].

15. Krakowski, R. A., "Summary of Presentations of the International Conference on Preparing the Ground for Renewal of Nuclear Energy," Plenum Press, New York, NY (1999) [also, Los Alamos National Laboratory document LA-UR-98-6015 (1998).

16. Krakowski, R. A., "Los Alamos Contributions to the IAEA Overall Comparative Assessment of Different Energy Systems and Their Potential Role in Long-Term Sustainable Energy Mixes," Los Alamos National Laboratory document LA-UR-99-627 (February 1999).

17. Krakowski, R. A., "Long-Term Global Trade Offs Related to Nuclear Energy," Intern. Conf. on Future Nuclear Systems, Global '99, Jackson, WY (August 29 - September 3, 1999). Los Alamos National Laboratory document LA-UR-98-5627 (December 2, 1998). 


\section{References}

[1] This reference number unused.

[2] Edmonds, J., and Reilly, J. M., Global Energy: Assessing the Future, Oxford University Press, New York (1985).

[3] Krakowski, R. A., "Global Energy Modeling in Support of Understanding Long-Term Nuclear (Materials) Futures," Los Alamos National Laboratory document LA-UR-96-1931 (June 5, 1996).

[4] Krakowski, R. A., "A Multi-Attribute Utility Approach to Generating Proliferation-Risk Metrics," Los Alamos National Laboratory document LA-UR-96-3620 (October 11, 1996).

[5] Krakowski, R. A., "Description of ERB (Edmonds, Reilly, Barns) Global E ${ }^{3}$ (Energy, Economics, Environment) Model," Los Alamos National Laboratory document LA-UR-98-1364 (April 1, 1998).

[6] Krakowski, R. A., "The Role of Nuclear Energy in Mitigating Greenhouse Warming," Global Foundation Intern. Conf. on Environment and Nuclear Energy, Washington, D.C. (October 27-19, 1997), Plenum Press (1998) [also, Los Alamos National Laboratory document LA-UR-97-4891 (December 12, 1997).

[7] Krakowski, R. A., "Re-Engineering Fission: Reactors for Safe, Globally Sustainable, Proliferation-Resistant, and Cost-Effective Nuclear Power," Workshop on Innovative Energy Systems and Carbon-Dioxide Stabilization, Aspen Global Climate Change Institute, Aspen CO, (July 14-24, 1998) [to be published 1999; also, Los Alamos National Laboratory document LA-UR-98-3768 (September 28, 1998)].

[8] Wagner, H.-F. (Chm.), "Global Energy Outlook: Key Issues Papaer \#1," International Symp. on Nuclear Fuel Cycle and Reactor Strategy; Adjusting to New Realities, Vienna, Austria (June 3-6, 1997).

[9] Arthur, E. D., Los Alamos Nuclear Materials Management Systems (NNMS) Project, private communication (1999).

[10] Krakowski, R. A., "Description of ERB (Edmonds, Reilly, Barns) Global E ${ }^{3}$ (Energy, Economics, Environment) Model," Los Alamos National Laboratory document LA-UR-98-1364 (April 1, 1998).

[11] Edmonds, J. A., Wise, M., and Barns, D. W., "The Cost and Effectiveness of Energy Agreements to Alter Trajectories of Atmospheric Carbon Dioxide Emissions," Energy Policy, 23(4/5), 309 (1995).

[12] Edmonds, J., and Reilly, J. M., "Global Energy Production and Use to the Year 2050," Energy, 8(6), 419 (1983).

[13] Edmonds, J. A.; Reilly, J. M.; Gardner, R. H.; and Brenkert, A., "Uncertainty in Future Global Energy Use and Fossil Fuel $\mathrm{CO}_{2}$ Emissions 1975-2075," U.S. Department of Energy Report DOE/NBB-0081 (December 1986). 
[14] Edmonds, J., and Reilly, J. M., "A Long-Term Global Energy Economic Model of Carbon Dioxide Release from Fossil Fuel Use," Energy Economics, 74 (April 1983).

[15] Edmonds, J. A.; Wise, M.; and MacCracken, C. N., "Advanced Energy Technology and Climate Change: An Analysis Using the Global Change Assessment Model (GCAM)," Battelle Pacific Northwest Laboratory report PNL-9798 (May 1994).

[16] Krakowski, R. A., "Global Energy Modeling in Support of Understanding Long-Term Nuclear (Materials) Futures," Los Alamos National Laboratory document LA-UR-96-1931 (June 5, 1996).

[17] Heising, C. D., Saragossi, I., and Sharafi, P., "A Comprehensive Assessment of the Economics and Proliferation Resistance of Advanced Nuclear Fuel Cycles," Energy, 5, 1121 (1980).

[18] Silvennoinen, P., and Vira, J., "Quantifying Relative Proliferation Risks from Nuclear Fuel Cycles," Prog. Nuclear Energy, 17(3), 231 (1986).

[19] Papazaglou, I. A.; Gyftopoulos, E. P.; Miller, M. M.; Rasmussen, N. C.; and H. A. Raiffa, "A Methodology for the Assessment of the Proliferation Resistance of Nuclear Power Systems," Massachusetts Institute of Technology report MIT-EL 78-021/022 (September 1978).

[20] Clarke, J. F., "The Cost and Benefit of Energy Technology in the Global Context," Proc. Conf. Technology Responses to Global Environmental Challenges: Energy Collaboration for the $21^{\text {st }}$ Century, p. 521, Kyoto Japan (November 6-8, 1991).

[21] Leontief, W., Input-Output Economics, Oxford University Press (1966).

[22] "Uranium: 1995 Resources, Production, and Demand," Nuclear Energy Agency of the Organization for Economic Co-operation and Development (NEA/OECD) and the International Atomic Energy Agency (IAEA) joint report, OECD, Paris (1996).

[23] Rogner, H.-H., "An Assessment of World Hydrocarbon Resources," Annual Review Energy and Environment, 22, 217 (1997).

[24] Hasselmann, K., Hasselmann, S., Giering, R., and Ocana, V., "Optimization of $\mathrm{CO}_{2}$ Emissions Using Coupled Integral Climate Response and Simplified Cost Models: A Sensitivity Study," Climate Change: Integrating Science Economics, and Policy, International Institute for Applied Systems Studies report CP-96-1 (1995).

[25] Cubasch, U., Hasselmann, K., Maier-Riemer, H., Mikolajewicz, E., Santer, B. D., and Sauser, R., " Time-Dependent Greenhouse Warming Computations with a Coupled Ocean-Atmosphere Model," Climate Dynamics 8, 55 (1992).

[26] Krakowski, R. A, "Los Alamos Contributions to the IAEA Overall Comparative Assessment of Different Energy Systems and Their Potential Role in Long-Term Sustainable Energy Mixes," Los Alamos National Laboratory document LA-UR-99-627 (February 1999).

[27] Nakicenovic, N. (Study Director), "Global Energy Perspectives to 2050 and Beyond," International Institute for Applied Systems Analysis (IIASA) and World Energy Council (WEC) report (1995); also Nakicenovic, A., Grübler, A., and McDonald, A. (Eds.), Global Energy Perspectives, Cambridge University Press, Cambridge, UK (1998). 
[28] Belyaev, L. S., Filippov, S. P., and Marchenko, O. V., "Studies on Potential Role of Different Energy Sources in the $21^{\text {st }}$ Century with the Use of the World Energy Model," IAEA Meeting on the Overall Comparative Assessment of Different Energy Systems and Their Potential Role in Long-Term Sustainable Energy Mixes, Vienna (September 30 October 2, 1997).

[29] Yamaji, K., and Fujii, "Analysis of the Role of Technology in Climate Change with Dynamic New Earth 21 Model," private communication (April 1998).

[30] Nordhaus, W. D., "To Slow or Not to Slow: the Economics of the Greenhouse Effect," The Economic Journal," 101, 929 (1991).

[31] Repetto, R., and Austin, D., :The Costs of Climate Protection: A Guide for the Perplexed," World Resources Institute report (1997).

[32] Bennett, L. (ed.), "Overall Comparative Assessment of Different Energy Systems and Their Potential Role in Long-Term Sustainable Mixes," IAEA Report (in preparation, 1999).

[33] Bos, E., Vu, My T., Massiah, E., Bulatao, R. A., 1993: World Population Projection Estimates and Projections with Related Demographic Statistics, The World Bank, Johns Hopkins University Press (1994-1995 Edition).

[34] "Projected Costs of Generating Electricity: Update 1997," OECD/NEA-IEA report (1998). 


\section{Nomenclature}

\begin{tabular}{|c|c|}
\hline $\begin{array}{l}\text { ACC } \\
\text { ADS } \\
\text { AEEI } \\
\text { BAU } \\
\text { BO } \\
\text { BR }\end{array}$ & $\begin{array}{l}\text { LWR-recyclable plutonium in spent fuel } \\
\text { Accelerator Driven Systems } \\
\text { Autonomous Energy Efficiency Improvement } \\
\text { Business-As-Usual scenario } \\
\text { Basic Option scenario } \\
\text { Breeding ration (LMR) }\end{array}$ \\
\hline $\begin{array}{l}\text { CHINA }^{+} \\
\text {COE(mill/kWeh) } \\
\text { CPE } \\
\text { CTAX }(\$ / \text { tonneC/15yr) } \\
\text { CY } \\
\text { D\&D }\end{array}$ & $\begin{array}{l}\text { China plus neighboring CPEs } \\
\text { Cost of Electricity } \\
\text { Centrally Planned Economy } \\
\text { linear rate of carbon tax increase } \\
\text { Calendar Year } \\
\text { Decommission and Decontamination }\end{array}$ \\
\hline DEV & $\begin{array}{l}\text { Developing regions }\left(\mathrm{ME}+\mathrm{CHINA}^{+}+\mathrm{NAFR}+\mathrm{SAFR}+\mathrm{LA}+\right. \\
\text { IND + SEA })\end{array}$ \\
\hline DNE21 & New Dynamic Earth $21^{\text {st }}$ Century Model ${ }^{29}$ \\
\hline DOE & Department of Energy \\
\hline$E^{3}$ & Energy-Economics-Ënvironment \\
\hline ED & Ecologically Driven scenario \\
\hline $\mathrm{EE}(\mathrm{EJ} / \mathrm{yr})$ & Electrical Energy demand \\
\hline EEU & Eastern Europe \\
\hline $\mathrm{EI}(\mathrm{MJ} / \$)$ & Energy Intensity. PE/GNP \\
\hline ER & (uranium) enrichment \\
\hline ERB & Edmonds, Reilly, Barns global E ${ }^{3}$ model $^{2}$ \\
\hline FC & Fuel Cycle \\
\hline $\mathrm{FE}(\mathrm{EJ} / \mathrm{yr})$ & Final (End-Use) Energy demand; also, Fossil Energy \\
\hline & Fuel Fabrication \\
\hline FP & Fission Product \\
\hline FSB & Fast Spectrum Burner (ADS, IFR) \\
\hline FSU & Former Soviet Union \\
\hline$f_{L W R}$ & Fraction NE produced by LWRs \\
\hline $\mathrm{f}_{\text {MOX }}^{\mathrm{f}}$ & (Final) volume core fraction of $L W R$ operated on $M O X$, also $f_{M}$ \\
\hline $\mathrm{f}_{\mathrm{NE}}$ & Fraction primary energy supplied by NE \\
\hline$f_{\text {O\&M }}^{N E}(1 / y r)$ & Annual O\&M charges as fraction of total capital costs \\
\hline GCC & Global Climate Change \\
\hline GEM10R & Global Economic Model 10 Regions $^{28}$ \\
\hline GDP(B $\$ / y r)$ & Gross Domestic Product \\
\hline GHG & Greenhouse Gas \\
\hline GNP(B $\$ / y r)$ & Gross National Product \\
\hline HEU & Highly Enriched Uranium \\
\hline $\mathrm{HV}$ & High Variant \\
\hline HYDRO & Hydroelectric \\
\hline IAEA & International Atomic Energy Agency \\
\hline IEA & International Energy Agency or Institute Energy Analysis \\
\hline IFR & Integral Fast Reactor \\
\hline IIASA & International Institute for Applied Systems Analysis \\
\hline IND & India or industrialized country \\
\hline IPCC & Intergovernmental Panel on Climate Change \\
\hline LA & Latin America \\
\hline LEU $^{*}$ & Low Enriched Uranium \\
\hline LMR & Liquid-Metal Reactor \\
\hline $\mathrm{LV}$ & Low Variant \\
\hline
\end{tabular}




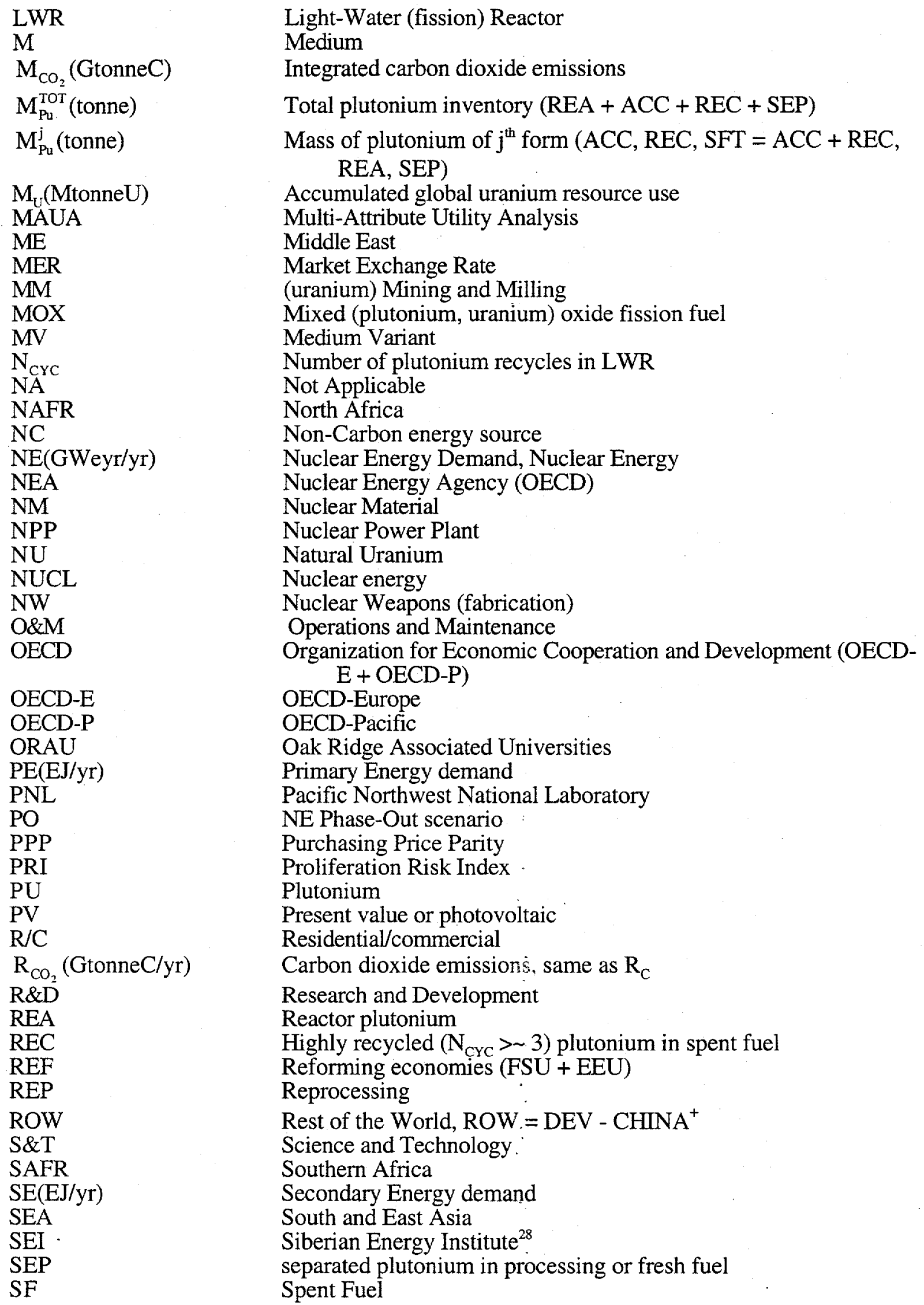


SFT

$\mathrm{TEC}(\mathrm{B} \$ \mathrm{yr})$

TH

TOT

TR

TX

$\mathrm{t}(\mathrm{yr})$

UTC $(\$ / W e)$

$<\mathrm{u}>$

$\mathrm{W}$ (GtonneC)

$\mathrm{W}_{\mathrm{o}}(\mathrm{GtonneC})$

WB

$\mathrm{WP}(\mathrm{yr})$

$\Delta \mathrm{T}(\mathrm{K})$

$\tau_{\text {MOX }}(\mathrm{yr})$
Total Spent Fuel $(\mathrm{ACC}+\mathrm{REC})$

Total Energy Cost

Thermal

Total, world

Total uranium Resources, KR + EAR-II + SR

carbon tax designator

Time

Unit Total Cost (of NPP), also UTC

Global average utility function for nuclear proliferation

Atmospheric carbon dioxide inventory, $\mathrm{ppmv}=\mathrm{W} / 2.13$

Integrated carbon dioxide emissions, same as $\mathrm{M}_{\mathrm{CO}_{2}}$, or normalizing atmospheric inventory (594 GtonneC at start of industrial revolution)

World Bank

Warning Period for (proliferation) detection

Global average surface temperature rise

Time constant for MOX implementation 


\section{Tables}

Table I. Summary of Key Outreach and Collaborative Activities Initiated Under the Nuclear Vision Project ${ }^{1}$ and the Integrated Global Energy Model LDRD (given in chronological order).

- Global'97 International Conference on Future Nuclear Systems: present two Los Alamos Nuclear Vision Project papers (Yokohama, Japan, October 6-9, 1997, LA-UR-97-2400 and LA-UR-97-2401);

- (Japan) Central Research Institute of Electric Power Industry (CRIEPI) briefing/funding pitch: (Tokyo, Japan, October 9, 1997);

- International Specialist Meeting on Future Nuclear Systems and Fuel Cycle Options: present Los Alamos Nuclear Vision Project papers (Tokyo Institute of Technology, October 13, 1997);

- Global Foundation International Conference on Environment and Nuclear Energy: present paper on role of nuclear energy in mitigating greenhouse warming (October 27-29, 1997, LA-UR-97-4891);

- IIASA: plan and implement Los Alamos Nuclear Vision Project input to IPCC process (Vienna, June 9, 1997, and December 16, 1997, LA-UR-97-4380);

- National Laboratory Briefings: LLNL (November, 7, 1997), SNLA (January 22, 1998);

- DOE/OE ${ }^{3} \mathrm{PA}$ : participate in DOE/OP $\mathrm{E}^{3}$ survey and workshop (Washington, DC, January 28-29, 1998); initiate teaming effort with BNL for DOE-solicited proposal to model technology innovation/diffusion;

- UC Berkeley Nuclear Engineering Colloquium (April 13, 1998) and LLBL Briefing (April 14, 1998) on Los Alamos Nuclear Vision and Integrated Energy Modelling Projects;

- Santa Fe Energy Seminar: Second US-Japan Workshop on Nuclear Futures - Post-Kyoto, (Santa Fe, NM, April 30 - May 1, 1998);

- Université Paris Dauphine Colloquium (invited) on the Role of Nuclear Energy in Mitigating Greenhouse Warming (Paris, France, May 27, 1998);

- Aspen Global Climate Change Institute Workshop on Innovative Energy Systems and $\mathrm{CO}_{2}$ Stabilization (invited, July 14-24, 1998, Aspen CO);

- Gordon Conference on the Future Role of Nuclear Energy (August 2-7, 1998, Salve Regina, RI);

- Global Foundation International Conference on Preparing the Ground for Renewal of Nuclear Power (invited, Paris, France, October 22-23, 1998); 
- Paul Scherrer Institut: Seminar and consultation (invited) on IAEA E ${ }^{3}$ Study, discussions on multi-regional $E^{3}$ modeling and on life-cycle energy assessments (November 23, 1998, and March 1, 1999, Vilingen, Switzerland).

- IAEA:

- Contribute to International Symposium on Nuclear Fuel Cycle and Reactor Strategies: Adjusting to New Realities (June 3-6, 1997, LA-UR-97-1716);

- Contribution to the 1998 "Comparative Assessment of Different Energy Sources and Their Potential Role in Long-Term Sustainable Energy Mixes", in conjunction with NEA/OECD, Siberian Energy Institute (SEI), and University of Tokyo:

-- Planning Meetings: September 29 - October 1, 1997; November 19-21, 1997; December 17-19, 1997 (Vienna);

-- Framing Meeting: April 6-8, 1998 (Los Alamos National Laboratory, Los Alamos, NM);

-- Baseline Meeting: May 25-26, 1998 (NEA, Paris, France);

-- First Results/Comparison Meeting: September 21, 1998 (Los Alamos National Laboratory, Los Alamos, NM);

-- Second Results/Comparison Meeting: November 16-20, 1998 (IAEA Headquarters, Vienna, Austria);

-- Finalization Meeting: February 24-26, 1999 (IAEA Headquarters, Vienna, Austria). 
Table II. Top-Level Comparison of Three Models Used in IAEA E ${ }^{3}$ Study $^{26,32}$

\begin{tabular}{|c|c|c|c|}
\hline Attribute/Model & $\mathbf{E R B}^{3}$ & DNE21 $^{1}$ & GEM10R $^{2}$ \\
\hline Paradigm & $\begin{array}{l}\text { "Top-Down" } \\
\text { (Econometric) }\end{array}$ & $\begin{array}{l}\text { "Bottom-Up" } \\
\text { (Technological) }\end{array}$ & $\begin{array}{l}\text { "Bottom-Up" } \\
\text { (Technological) }\end{array}$ \\
\hline $\begin{array}{l}\text { Energy Resources } \\
\text { - Fossil } \\
\text { - Nuclear }\end{array}$ & $\begin{array}{l}\text { Edmonds }{ }^{2} \text { or Rogner }{ }^{23} \\
\text { Uranium Institute }^{22}\end{array}$ & $\begin{array}{l}\text { Rogner }^{23} \\
\text { Uranium Institute }^{22}\end{array}$ & $\begin{array}{l}\text { Rogner }^{23} \\
\text { Uranium Institute }^{22}\end{array}$ \\
\hline Regions (micro/macro) & $13 / 3$ & $10 / 3$ & $10 / 4$ \\
\hline $\begin{array}{l}\text { Time } \\
\text { - } \text { Base } \\
\text { - Horizon } \\
\text { - Increments }\end{array}$ & $\begin{array}{l}1975 \\
2095 \\
15\end{array}$ & $\begin{array}{c}1990 \\
2100 \\
10\end{array}$ & $\begin{array}{l}1990 \\
2100 \\
25\end{array}$ \\
\hline $\begin{array}{l}\text { Object Function/ } \\
\text { Convergence criteria }\end{array}$ & World fossil prices & $\begin{array}{l}\text { Total discounted } \\
\text { energy cost over } \\
\text { full-time horizon. }\end{array}$ & $\begin{array}{l}\text { Total discounted } \\
\text { energy cost over } \\
\text { each period. }\end{array}$ \\
\hline Discount rate & $5 \% / y r$ (when used) & $5 \% / \mathrm{yr}$ & $5 \% / y r$ \\
\hline $\begin{array}{l}\text { Energy structure, } \mathrm{PE} \text { and } \\
\text { SE same, FE differs }\end{array}$ & $\begin{array}{l}\text { Residential/ } \\
\text { Commercial, Industry, } \\
\text { Transportation }\end{array}$ & $\begin{array}{l}\text { NA, uses SE } \\
\text { demand from ERB }\end{array}$ & $\begin{array}{l}\text { Heat, Mechanical, } \\
\text { Chemical, } \\
\text { Electrical; uses SE } \\
\text { demand and part of } \\
\text { FE demand from } \\
\text { ERB, or SEI } \\
\text { demand function. }\end{array}$ \\
\hline Population & $\mathrm{WB}^{33}$, analytic fit & $\mathrm{WB}^{33}$, direct & $\mathrm{WB}^{33}$, direct \\
\hline $\begin{array}{cl}\text { Per-capita GNP } \\
- & \text { Source } \\
- & \text { Kind } \\
\end{array}$ & $\begin{array}{c}\text { IIASA }^{27} \text {, indirect fit } \\
\text { MER }\end{array}$ & $\begin{array}{l}\text { NA } \\
\text { NA }\end{array}$ & $\begin{array}{c}\text { IIASA }^{27} \text {, direct } \\
\text { PPP }\end{array}$ \\
\hline $\begin{array}{c}\text { Technology costs } \\
-\quad \text { Electricity } \\
-\quad \text { Other }\end{array}$ & $\begin{array}{c}\mathrm{NEA}^{34} / \mathrm{ERB}^{2} \\
\mathrm{ERB}^{2}\end{array}$ & $\begin{array}{c}\mathrm{NEA}^{34} \\
\text { DNE}_{21}{ }^{28}\end{array}$ & $\begin{array}{l}\text { NEA }^{34} \\
\text { GEM10R }^{29}\end{array}$ \\
\hline $\begin{array}{l}\text { Conversion efficiencies } \\
\text { - Nuclear } \\
\text { - Gas } \\
\text { - } \text { Coal }\end{array}$ & $\begin{array}{c}0.35 \rightarrow 0.40 \\
0.40 \\
0.40\end{array}$ & $\begin{aligned} & 0.35 \\
0.46 & \rightarrow 0.51 \\
0.39 & \rightarrow 0.50\end{aligned}$ & $\begin{array}{l}0.33 \rightarrow 0.35 \\
0.45 \rightarrow 0.55 \\
0.36 \rightarrow 0.50\end{array}$ \\
\hline $\begin{array}{l}\text { Renewable Energy (RE) } \\
\text { - Commercial } \\
\text { - } \quad \text { Non-commercial }\end{array}$ & $\begin{array}{l}\text { Yes } \\
\text { No }\end{array}$ & $\begin{array}{l}\text { Yes } \\
\text { No }\end{array}$ & $\begin{array}{l}\text { Yes } \\
\text { Yes }\end{array}$ \\
\hline AEEI & $\begin{array}{r}1975-2005,1.00 \% / \mathrm{yr} \\
2005-2050,0.50 \% / \mathrm{yr} \\
2050-2095, \text { linear } \\
\text { increase to } \\
0.8 \% / \mathrm{yr}^{(\mathrm{a})}\end{array}$ & NA & NA \\
\hline
\end{tabular}

(a) Rate at which SE $\rightarrow$ FE conversion efficiency improves with time; non-price origins. 
Table IV. Absolute Values of Key Parameters Used to Generate Normalized Sensitivity Diagrams (Figs. 23 and 24) for Year 2095

\begin{tabular}{|l|r|}
\hline \multicolumn{1}{|c|}{ Parameter } & Value \\
\hline Carbon-dioxide emission rate, $\mathrm{R}_{\mathrm{CO}_{2}}(\mathrm{GtonneC} / \mathrm{yr})$ & 19.8 \\
\hline Atmospheric carbon-dioxide inventory, W(GtonneC) & 1631.6 \\
\hline Average global surface temperature increase, $\Delta \mathrm{T}(\mathrm{K})$ & 2.6 \\
\hline Total global plutonium, $\mathrm{M}_{\mathrm{Pu}}^{\mathrm{TOT}}(\mathrm{ktonnePu})$ & 15.3 \\
\hline Proliferation Risk Index, PRI & 0.14 \\
\hline Electrical energy as fraction of primary energy, EE/PE & 0.15 \\
\hline Nuclear energy as fraction of primary energy, NE/PE & 0.19 \\
\hline
\end{tabular}

